\title{
Profiling the molecular signature of Satellite Glial Cells at the single cell level reveals high similarities between rodent and human
}

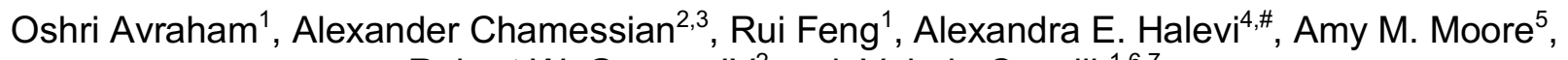
Robert W. Gereau IV ${ }^{2}$ and Valeria Cavalli ${ }^{1,6,7}$

1. Department of Neuroscience, Washington University School of Medicine, St Louis 63110, Missouri, USA

2. Washington University Pain Center and Department of Anesthesiology, Washington University School of Medicine, St Louis 63110, Missouri, USA

3. Department of Neurology, Washington University School of Medicine, St Louis 63110, Missouri, USA

4. Department of Plastic and Reconstructive Surgery, Washington University School of Medicine, St Louis 63110, Missouri, USA

5. Department of Plastic and Reconstructive Surgery, The Ohio State University, Columbus Ohio, USA

6. Hope Center for Neurological Disorders, Washington University School of Medicine, St. Louis, Missouri 63110, USA

7. Center of Regenerative Medicine, Washington University School of Medicine, St. Louis, Missouri 63110, USA

${ }^{*}$ Correspondence to:

Valeria Cavalli, Department of Neuroscience, Washington University School of Medicine, Campus Box 8108, 660 S. Euclid Ave, St. Louis, MO 63110-1093 Phone: 314362 3540, Fax: 314362 3446, E-mail: cavalli@wustl.edu

\# Current address: Department of Surgery, New York Presbyterian Queens

\section{FUNDING INFORMATION}

This research was funded by in part by a post-doctoral fellowship from The McDonnell Center for Cellular and Molecular Neurobiology to O.A, by NIH grant NS042595 to R.G, by The McDonnell Center for Cellular and Molecular Neurobiology to V.C., by a Pilot Project Award from the Hope Center for Neurological Disorders at Washington University to V.C. and by NIH grants NS111719 and NS115492 to V.C. 


\begin{abstract}
Peripheral sensory neurons located in dorsal root ganglia relay sensory information from the peripheral tissue to the brain. Satellite glial cells (SGC) are unique glial cells that form an envelope completely surrounding each sensory neuron soma. This organization allows for close bidirectional communication between the neuron and it surrounding glial coat. Morphological and molecular changes in SGC have been observed in multiple pathological conditions such as inflammation, chemotherapy-induced neuropathy, viral infection and nerve injuries. There is evidence that changes in SGC contribute to chronic pain by augmenting neuronal activity in various rodent pain models. SGC also play a critical role in axon regeneration. Whether findings made in rodent model systems are relevant to human physiology have not been investigated. Here we present a detailed characterization of the transcriptional profile of SGC in mouse, rat and human at the single cell level. Our findings suggest that key features of SGC in rodent models are conserved in human. Our study provides the potential to leverage on rodent SGC properties and identify potential targets for the treatment of nerve repair and alleviation of painful conditions.
\end{abstract}

\title{
KEYWORDS
}

Satellite glial cells, DRG, pain, human, mouse, rat, transcription, single cell RNAseq 


\section{INTRODUCTION}

Peripheral sensory neurons located in dorsal root ganglia relay sensory information from the peripheral tissue to the brain. Satellite glial cells (SGC) are unique in that they form an envelope that completely surround each sensory neuron (Hanani \& Spray, 2020; Pannese, 1981, 2002, 2010). The sensory neuron and its surrounding SGC coat thus form a distinct morphological and functional unit not found in the central nervous system (Hanani \& Spray, 2020). Multiple SGC surround one single neuron, and the number of SGC surrounding sensory neurons increases with increasing soma size (Ledda, De Palo, \& Pannese, 2004; Pannese, 1964, 2010). This organization allows for close bidirectional communication, which is likely critical for neuronal homeostasis. Morphological and molecular changes are elicited in SGC by pathological conditions such as inflammation, chemotherapy-induced neuropathic pain as well as nerve injuries (Avraham, Deng, et al., 2020; Carozzi et al., 2010; Carozzi et al., 2013; Cherkas et al., 2004; Hanani, 2005; Hanani, Huang, Cherkas, Ledda, \& Pannese, 2002; S. E. Jager et al., 2020; Warwick \& Hanani, 2013). These studies point to the contribution of SGC to chronic pain (Gazerani 2021). In addition, in aged animals, extensive portions of the neuronal surface are not covered by SGCs (Martinelli, Sartori, De Palo, Ledda, \& Pannese, 2006; Pannese, 2010), which could contribute to impaired sensory function in aging. Injury-induced changes in SGC contribute to neuronal excitability and nociception (Hanani \& Spray, 2020; L. Y. Huang, Gu, \& Chen, 2013; Kung et al., 2013), as well axon regeneration (Avraham, Deng, et al., 2020).

SGC represent one of the two main glial cell type in the PNS, the other being Schwann cells. Both cell types derive from the neural crest. Although it was proposed that SGCs represent a subpopulation of cells in the Schwann cell lineage (George, Ahrens, \& Lambert, 2018), our recent analysis of SGC at the single cell level revealed that SGC are transcriptionally distinct from Schwann cells and share functional and molecular features with astrocytes (Avraham, Deng, et al., 2020). The main channel expressed by SGC and astrocytes is the inwardly rectifying potassium channel (Kir4.1). Reducing Kir4.1 in SGC expression leads to pain-like behavior (Vit, 
Ohara, Bhargava, Kelley, \& Jasmin, 2008) and loss of Kir4.1 in astrocytes also affect neuronal activity (Cui et al., 2018). Another common feature between SGC and astrocytes is functional coupling by gap junctions, with SGC surrounding the same neuron connected by gap junctions (Christie et al., 2015; Donegan, Kernisant, Cua, Jasmin, \& Ohara, 2013; Hanani, 2005; T. Y. Huang, Cherkas, Rosenthal, \& Hanani, 2005). The number of gap junctions between SGC increases after nerve transection (Hanani et al., 2002) and in models of chemotherapy-induced neuropathic pain (Warwick \& Hanani, 2013). Similarly to astrocytes, SGC are reactive to various pathological conditions and increase expression of the glial fibrillary acidic protein (GFAP) (Christie et al., 2015; F. Y. Liu et al., 2012; Woodham, Anderson, Nadim, \& Turmaine, 1989).

Most of the available information on SGC function has been obtained in rodents, which limits the potential for clinical translation. The unique molecular signature of human SGC has not been described and their functional roles are not well established. However, some evidence points to a crucial role of SGC in human pathological conditions and non-human primate models. In human patients with Friedreich Ataxia, an autosomal recessive neurodegenerative disease, SGC proliferate, form gap junctions and abnormal multiple layers around the neurons (Koeppen, Becker, Qian, \& Feustel, 2017; Koeppen, Ramirez, Becker, \& Mazurkiewicz, 2016). Friedreich Ataxia is proposed to result from the loss of bidirectional trophic support between SGC and neurons (Koeppen et al., 2016). SGC also play a role in viral infection such as herpes simplex virus or varicella zoster virus (Zerboni, Ku, Jones, Zehnder, \& Arvin, 2005). Varicella reactivation causes painful skin eruptions (shingles) and herpes reactivation cause mucocutaneous lesions and may also result in neuralgia (Fatahzadeh \& Schwartz, 2007). SGC might also be implicated in HIV-1 infection, the virus that causes AIDS, in which peripheral neuropathy and pain are common. Macaques infected with simian immunodeficiency virus display an upregulation of GFAP in SGC (Mangus et al., 2019). Infection with viruses of the coronavirus family also implicates SGC. Hemagglutinating encephalomyelitis virus belongs to the family of coronavirus and was shown to replicate within rat sensory neurons and accumulate in lysosome-like structures 
within SGC, suggesting that SGC may restrict the local diffusion of the virus (Y. C. Li, Bai, Hirano, Hayashida, \& Hashikawa, 2012). These findings are consistent with the recent observation that the coronavirus receptor ACE2 is expressed in a subset of human sensory neurons (Shiers et al., 2020) and suggest that after entering neurons, the virus may be taken up by SGC and accumulate in intracellular organelles. DRG sensory neurons and their SGC coat represent thus a potential target for multiple viral invasions in the peripheral nervous system.

The accumulating evidences pointing to the contribution of SGC to chronic pain and nerve repair suggest that a better understanding of SGC responses to various insults and how SGC interact with neurons and other cells in the DRG will be important for future targeted therapies to treat nerve injuries. Therefore, to achieve translation of findings in rodent models, a direct comparison with human tissues is needed. Human sensory ganglia have been molecularly characterized mainly in bulk sequencing of DRG samples or focused on expression of specific markers in sensory neurons (North et al., 2019; Shiers et al., 2020; Tavares-Ferreira et al., 2021). Several studies have revealed similarities and difference between mouse and human sensory neurons (Davidson et al., 2014; Lang et al., 2015; Lindborg et al., 2018; Michalowsky, Hoffmann, \& Kostev, 2019; Rostock, Schrenk-Siemens, Pohle, \& Siemens, 2017; Tavares-Ferreira et al., 2021; Valtcheva et al., 2016) However, SGC have not yet been investigated in detail in human. Here we present a single cell level analysis of SGC in mouse, rat and human. We find that some of the key features of SGC, including their similarities with astrocytes and the enrichment of biological pathways related to lipid metabolism are largely conserved between rodent and human. Our study highlights the potential to leverage on rodent SGC properties and unravel novel mechanisms and potential targets for treating nerve injuries and other pathological conditions.

\section{MATERIALS AND METHODS}

\section{Animals and procedures}


All animals were approved by the Washington University School of Medicine Institutional Animal Care and Use Committee (IACUC) under protocol A3381-01. All experiments were performed in accordance with the relevant guidelines and regulations. All experimental protocols involving rats and mice were approved by Washington University School of Medicine (protocol \#20180128). Mice and rats were housed and cared for in the Washington University School of Medicine animal care facility. This facility is accredited by the Association for Assessment \& Accreditation of Laboratory Animal Care (AALAC) and conforms to the PHS guidelines for Animal Care. Accreditation - 7/18/97, USDA Accreditation: Registration \# 43-R-008. 8-12 weekold female C57BI/6 mice and adult male Lewis rats were used for single cell RNAseq studies.

\section{Single cell RNAseq in mouse and rat}

L4 and L5 DRG's from mice and rat were collected into cold Hank's balanced salt solution (HBSS) with $5 \%$ Hepes, then transferred to warm Papain solution and incubated for $20 \mathrm{~min}$ in $37^{\circ} \mathrm{C}$. DRG's were washed in HBSS and incubated with Collagenase for 20 min in $37^{\circ} \mathrm{C}$. Ganglia were then mechanically dissociated to a single cell suspension by triturating in culture medium (Neurobasal medium), with Glutamax, PenStrep and B-27. Cells were washed in HBSS + Hepes $+0.1 \%$ BSA solution, passed through a 70 -micron cell strainer. Hoechst dye was added to distinguish live cells from debris and cells were FACS sorted using MoFlo HTS with Cyclone (Beckman Coulter, Indianapolis, IN). Sorted cells were washed in HBSS + Hepes $+0.1 \% B S A$ solution and manually counted using hemocytometer. Solution was adjusted to a concentration of 500cell/microliter and loaded on the 10X Chromium system. Single-cell RNA-Seq libraries were prepared using GemCode Single-Cell 3' Gel Bead and Library Kit (10x Genomics). A digital expression matrix was obtained using 10X's CellRanger pipeline (Build version 3.1.0) (Washington University Genome Technology Access Center). Quantification and statistical analysis were done with Partek Flow package (Build version 9.0.20.0417). 
Filtering criteria: Low quality cells and potential doublets were filtered out from analysis using the following parameters: total reads per cell: $600-15000$, expressed genes per cell: $500-$ 4000 , mitochondrial reads $<10 \%$. A noise reduction was applied to remove low expressing genes $<=1$ count. Counts were normalized and presented in logarithmic scale in CPM (count per million) approach. An unbiased clustering (graph-based clustering) was done and presented as t-SNE (tdistributed stochastic neighbor embedding) plot, using a dimensional reduction algorithm that shows groups of similar cells as clusters on a scatter plot. Differential gene expression analysis performed using an ANOVA model; a gene is considered differentially expressed (DE) if it has a false discovery rate (FDR) step-up ( $p$ value adjusted). $p \leq 0.05$ and a Log2fold-change $\geq \pm 2$. The data was subsequently analyzed for enrichment of GO terms and the KEGG pathways using Partek flow pathway analysis. Partek was also used to generate figures for t-SNE and scatter plot representing gene expression.

\section{Human tissue collection}

For snRNAseq, human dorsal root ganglia (hDRG) were obtained from Anabios, Inc (San Diego, CA). For this study, L4 lumbar DRG was removed from a 44-year-old Asian female who died of a cerebrovascular accident and who did not have a history of other neurological or metabolic disease. The tissue was immediately snap-frozen and stored at $-80 \mathrm{C}$ until use.

For immunohistochemistry studies, human DRG were obtained from organ donors with full legal consent for use of tissue in research, and in compliance with procedures approved by Mid-America Transplant (St. Louis, MO). The Human Research Protection Office at Washington University in St. Louis provided an Institutional Review Board waiver. Details regarding the donors are included below: 


\begin{tabular}{cccccc}
\hline Age & Sex & Race & DRG level & BMI & COD \\
\hline 46 & Female & White & L1,2 & 20.91 & Anoxia \\
44 & Female & Middle Eastern & L1,4 & 22.2 & CVA/SAH \\
53 & Female & White & L4,5 & 25.48 & CVA/Stroke \\
54 & Female & White & L1-5 & 25.9 & CVA/Stroke \\
\hline
\end{tabular}

\section{Single nucleus RNAseq from human sample}

To make the tissue suitable for nuclei isolation, the entire DRG was processed into smaller pieces by cryopulverization using the CryoPrep (Covaris; CP02). Nuclei were isolated according to Martelotto with some modifications (Martelotto \& Martelotto, 2020). We elected to apportion the cryopulverized tissue and process the portions in parallel using two different buffers in order to evaluate potential effects on nuclei representation. One homogenization buffer was EZ Nuclei Lysis Buffer (Sigma; NUC101-1KT) with 0.5\% RNasin Plus (Promega; N2615), 0.5\% SUPERaseIn (ThermoFisher; AM2696) and 1mM DTT (Habib et al., 2017). The other homogenization buffer was CST buffer (NaCl2 146 mM, Tris $\mathrm{HCl}$ pH 7,5 10 mM, CaCl2 1mM, MgCl2 21 mM, 0.49\% CHAPS (Millipore-Sigma), 0.01\% BSA, 0.5\% SUPERasin-in, 0.5\% RNasin Plus), as described in Slyper et al. (Slyper et al., 2020). Using the EZ buffer, the samples were homogenized on ice using 18 strokes of Pestle A followed by 18 strokes of Pestle B. The homogenate was filtered through a $50 \mathrm{~m}$.um filter (Sysmex; 04-004-2327) into a $2 \mathrm{~mL}$ microcentrifuge tube (Eppendorf; 022431048). An additional $0.5 \mathrm{~mL}$ of homogenization buffer was used to wash the Dounce homogenizer and filter. The sample was then placed on ice while the remaining samples were processed. The sample was centrifuged at $500 \mathrm{~g}$ at $4^{\circ} \mathrm{C}$ for 5 mins to obtain a crude pellet containing spinal nuclei. The supernatant was removed and discarded, being careful to not disturb the pellet. The pellet was resuspended in $1.5 \mathrm{~mL}$ of Homogenization Buffer and allowed to sit on ice for 5 mins. at $500 \mathrm{~g}, 4^{\circ} \mathrm{C}$ for 5 mins. This wash step was repeated twice more for a total of 3 
washes. The final pellet was resuspended in $0.5 \mathrm{~mL}$ of $\mathrm{NRB}$ containing $6 \mu \mathrm{M} \mathrm{4}$ ',6-diamidino-2phenylindole (DAPI, ThermoFisher; D1306). The suspension was filtered through a $20 \mu \mathrm{m}$ filter (Sysmex; 04-004-2325) into a polypropylene tube and kept on ice. Using the CST buffer, the samples were homogenized on ice using 18 strokes of Pestle A followed by 18 strokes of Pestle B in $1 \mathrm{~mL}$ of CST buffer. The homogenate was filtered through a $50 u \mathrm{~m}$ filter into a $15 \mathrm{~mL}$ conical. An additional $1 \mathrm{~mL}$ was used to wash the filter and then $3 \mathrm{~mL}$ of CST was added, bringing the total volume to $5 \mathrm{~mL}$. The suspension was spun down at $500 \mathrm{~g}$ for 5 mins at $4^{\circ} \mathrm{C}$. The supernatant was removed and the pellet was resuspended in $0.5 \mathrm{~mL}$ of CST containing $6 \mu \mathrm{M}$ of DAPI. The suspension was filtered through a $20 \mu \mathrm{m}$ filter into a polypropylene tube and kept on ice. Fluorescence Activated Nuclear Sorting (FANS) was performed to purify nuclei from debris on a FACSAria II (BD). Gates were set to isolate DAPI+ singlet nuclei based on forward scatter and side scatter as well as fluorescence intensity. The instrument was set to 45 pounds per square inch (psi) of pressure and a $85 \mu \mathrm{m}$ nozzle was used, with sterile PBS sheath fluid. Nuclei were sorted into a $1.5 \mathrm{ml}$ microcentrifuge tube containing $15 \mu \mathrm{l}$ of $\mathrm{NRB}$ at $4^{\circ} \mathrm{C}$. For each sample, 18,000 events were sorted into the collection tube. The sorted nuclei and NRB total volume was approximately $45 \mathrm{ul}$, allowing for the entire loading of the suspension into the Chromium Single Cell 3' v3 solution (10x Genomics) without any further manipulation. 10x libraries were processed according to the manufacturer's instructions. Completed libraries were run on the Novaseq 6000 (Illumina). A digital expression matrix was obtained using 10X's CellRanger pipeline as above.

\section{Tissue preparation and immunohistochemistry}

After isolation of mouse DRG, tissue was fixed using $4 \%$ paraformaldehyde for $1 \mathrm{~h}$ at room temperature. Tissue was then washed in PBS and cryoprotected using 30\% sucrose solution at $4 \mathrm{C}$ overnight. Next, the tissue was embedded in O.C.T., frozen, and mounted for cryosectioning. Mouse frozen sections were cut at $12 \mu \mathrm{m}$ for subsequent staining. Freshly dissected human DRG 
were sectioned to $40 \mu \mathrm{m}$, fixed and stored as free floating in cryoprotectant. Mouse DRG sections mounted on slides and human floating DRG sections were washed $3 x$ in PBS and then blocked for in solution containing $10 \%$ donkey serum in $0.1 \%$ Triton-PBS for $1 \mathrm{~h}$. Next, sections were incubated overnight in blocking solution containing primary antibody. The next day, sections were washed $3 x$ with PBS and then incubated in blocking solution containing a secondary antibody for $1 \mathrm{~h}$ at room temperature. Finally, sections were washed $3 \mathrm{x}$ with PBS and mounted using ProLong Gold antifade (Thermo Fisher Scientific). Images were acquired at 10x or 20x using a Nikon TE2000E inverted microscope. Antibodies were as follow: Tubb3/ßIII tubulin antibody (BioLegend catalog \#802001, RRID:AB_291637), Fabp7 (Thermo Fisher Scientific Cat \#PA5-24949, RRID:AB_2542449), Fasn (Abcam, Catalog \#ab128870). Stained sections with only secondary antibody were used as controls.

\section{RESULTS}

\section{Profiling DRG cells from human, mouse and rat at the single cell level}

To define the similarities and differences between SGC across different species, we performed snRNA seq of L4 human DRG and scRNA-seq of L4,L5 mouse and rat DRG using the Chromium Single Cell Gene Expression Solution (10x Genomics) (Fig. 1a). We chose to perform scRNAseq in rodents because we previously showed that this method efficiently captures SGC (Avraham, Deng, et al., 2020; Avraham, Feng, Ewan, Zhao, \& Cavalli, 2020). We opted for snRNAseq in human DRG because the tissue was frozen and the large size of cells in human may limit their capture rate in the 10x platform. The number of sequenced human nuclei from one donor (female, 44 years of age) was 6,974 from 2 technical replicates, with an average of 100,989 mean reads per cell, 2,060 mean genes per cell and a total of 27,228 genes detected. The number of sequenced mouse cells from two biologically replicates (pooled DRG's from 3 mice for each replicate) was 6,343 with an average of 65,378 mean reads per cell, 1,510 mean genes per cell 
and a total of 18,130 genes detected. The number of sequenced cells from two biologically independent rats was 15,892 with an average of 41,594 mean reads per cell, 2,132 mean genes per cell and a total of 17,137 genes detected. Low quality cells and doublets were filtered out from downstream analysis (see filtering criteria in the methods). To identify cluster-specific genes, we calculated the expression difference of each gene between that cluster and the average in the rest of the clusters (ANOVA fold change threshold >1.5). Examination of the cluster-specific marker genes revealed major cellular subtypes including neurons, SGC, endothelial cells, Schwann cells, pericytes, smooth muscle cells, macrophages, mesenchymal cells and connective tissue cells (Fig. 1a, table 1) (Avraham et al, 2020). Human specific marker genes were used to classify cell populations; macrophages (CD163), Mesenchymal cells (Pdgfra), endothelial cells (Flt1), connective tissue/mesenchymal (Col1a1), Myelinating Schwann cells (Prx), Myelinating/non-Myelinating Schwann cells and SGC (S100b), T-cells (CD2) and Smooth muscle cells (Myocd) (Supplementary Fig. 1a and Table 1). Rodents had slightly different cell types and markers; macrophages (CD68), pericytes (Kcnj8), Neurons (Tubb3), SGC (Cdh19) (Supplementary Fig. $1 \mathrm{~b}, \mathrm{c}$ and Table 1). We previously showed that although the actual percentage of neuronal cells in the mouse DRG is about $12 \%$, the number of neurons detected in our scRNAseq analysis was only about 1\% (Avraham, Deng, et al., 2020; Avraham, Feng, et al., 2020), which might be a result of neuronal damage during the tissue dissociation process or the fact that sensory neurons are relatively large cells and are less amenable for single cell studies (Fig. 1a). In the rat samples, only $0.5 \%$ of cells were neurons and no neuronal cells were detected in the human sample (Fig. 1a). Nevertheless, our protocol achieved recovery of SGC from all species with $11 \%$ in human, $55 \%$ in mouse and $74 \%$ in rat (Fig. 1a), allowing us to compare the molecular profile of SGC across species. We recently described that Fabp7 (Fatty acid binding protein 7) is a specific marker gene for SGC and that the FABP7 protein is highly enriched in mouse SGC compared to other cells in the DRG (Avraham et al, 2020). t-SNE plots overlaid for FABP7 further demonstrates that FABP7 is also enriched in human and rat SGC (Fig. 1b). 
Immunostaining of DRG sections from mouse and human for FABP7 revealed the specific labelling of SGC surrounding sensory neurons (Fig. 1c,d). A similar staining was observed in three different human donors, suggesting that the snRNAseq results from one donor is fairly representative.

\section{Expression of SGC specific marker genes in rodents and human DRG}

We next examined the expression of known SGC marker genes in rodent and human. Cells in the clusters identified as SGC were then pooled together. We identified 727 SGC in human, 3,460 SGC in mouse and 8,428 SGC in rat (Fig. 2a-c). t-SNE plots overlaid with FABP7 demonstrated that while almost all SGC in rodents express high levels of FABP7, mouse (92\%) and rat (88\%), only about half of SGC (54\%) expressed FABP7 in human (Fig. 2a-d). Cadherin19 (Cdh19) has been described as a unique SGC marker in rat Schwann cell precursors (Takahashi \& Osumi, 2005) and in adult rat SGC (George et al., 2018). We found that the SGC marker gene Cdh19 was expressed in all human SGC (98\%), whereas only half of SGC in rodents expressed this gene (56\% in mouse and $48 \%$ in rat (Fig. 2a-d). Glutamine synthetase (Glul/GS) has been suggested as a SGC specific marker in rat (Miller, Richards, \& Kriebel, 2002) and mouse DRG (S. B. Jager, Pallesen, \& Vaegter, 2018; S. E. Jager et al., 2020). Our previous finding indicated a nonspecific expression of GS in almost all cells in the DRG at the transcript level (Avraham, Deng, et al., 2020). Our analysis suggests differences in GS expression between species with more than half of SGC expressing GS in rodents ( $60 \%$ ), and only around $30 \%$ in human (Fig. 2a-d).

One of the characteristics of SGC, which is similar to astrocytes, is the ability to control the microenvironment via expression of transporters and ion channels (Hanani \& Verkhratsky, 2021). The potassium channel Kir4.1 is a known marker of SGC. Kir4.1/Kcnj10 is expressed in rat SGC and influence the level of neuronal excitability, which has been associated with neuropathic pain conditions (Vit et al., 2008). Our analysis demonstrates that Kir4.1 is expressed 
in almost half of mouse SGC (42\%), whereas it is expressed in fewer SGC in rat (6\%) and human $(11 \%)$ (Fig. 2a-d). Interestingly, we found that the potassium channel Kir3.1/Kcnj3 is widely expressed in human (85\%) but not in rodents SGC (Fig. 1d). The diversity in potassium channel expression in SGC might suggest a special role for this channel in defining the physiological characteristics of SGC across species. Another potassium channel that has been shown to be expressed specifically in rat SGC is SK3 (Vit et al., 2008). However, our analysis suggests that only a small subset of rat SGC (12\%) and human SGC (5\%) express SK3 (Fig.2d), whereas mouse SGC do not express SK3 (Fig.2d).

Another main property of SGC that is shared with astrocytes is functional coupling by gap junctions, with SGC surrounding the same neuron connected by gap junctions (Hanani \& Spray, 2020; T. Y. Huang et al., 2005). Gap junction protein alpha 1 (GJA1/CX43) is the most abundant connexin (Cx) and was shown to modulate pain responses (Spray et al., 2019). We found that Cx43 is expressed in a majority of rat SCG (60\%) but less prevalent in mouse (30\%) and human (13\%). Other known gap junctions proteins expressed in SGC include Cx32, followed by Cx30.2, Cx37, Cx26, Cx30, Cx45 and Cx36 (Hanani \& Spray, 2020). Although these gap junctions genes were reported to be expressed in SGC, we found that less then $5 \%$ of SGC expressed them across all species, except for Cx30.2, which was expressed in 35\% of mouse SGC.

Membrane channels related to gap junctions are Pannexins (Panx), which do not form cell-to-cell channels but are highly permeable to ATP (L. Y. Huang et al., 2013). Pannexin1 (Panx1) was reported to be expressed in sensory ganglia where it is increased in pain models (Spray et al., 2019), with low Panx1 expression in both mouse and human (6\%) (Fig. 2d). These observations indicate variability in Gap junction gene expression between rodent and human might suggest functional differences in SGC communication. SGC also express glial fibrillary acidic protein (GFAP) and similarly to astrocytes, GFAP expression is increased under pathological conditions, which can have a protective function (Woodham et al, 1989). In mouse, Gfap is one of the top upregulated genes in SGC upon nerve injury (Avraham et al, 2020)(Christie 
et al., 2015; Fenzi, Benedetti, Moretto, \& Rizzuto, 2001). However, in uninjured DRG, the distribution of Gfap was relatively low, with $\sim 20 \%$ expression in rat, $1.5 \%$ in mouse and undetectable levels in human DRG (Fig. 2d).

While SGC do not typically myelinate neuronal soma, some myelin associated genes Mpz, Mbp, and Plp1 are highly expressed in SGC (Avraham, Deng, et al., 2020). Proteolipid protein (PIp1) is the major myelin proteins in the central and peripheral nervous system. Plp1 is expressed in all rodents SGC and in half of human SGC (Fig. 2d). Another gene that is expressed in all rodent SGC and $76 \%$ of human SGC is apolipoprotein $E$ (ApoE) (Fig. 2d). ApoE is a multifunctional protein, mainly involved in lipid synthesis and transport. High levels of ApoE production occur in the brain, where it is primarily synthesized by astrocytes (Fernandez et al, 2019). We recently found that one of the genes enriched in mouse SGC is fatty acid synthase (Fasn) (Avraham et at, 2020), which controls the committed step in endogenous fatty acid synthesis (Dean \& Lodhi, 2018). Examination of Fasn transcript expression reveal high distribution in rat SGC (70\%) and lower in mouse (40\%) and human (30\%) SGC (Fig. 2d). Immunostaining for FASN in DRG sections reveals its specific expression in SGC around neurons (TUJ1) in both human (Fig. 2e) and mouse (Fig. 2f) DRG tissue. These results suggest that the expression of genes related to lipid metabolism and transport in SGC, such as FASN and ApoE, are conserved between rodents and human.

\section{SGC from rodent and human share functional properties}

To further examine the biological properties of SGC across species, we calculated the top differentially expressed genes in SGC in human (2,946 genes), mouse (2,229 genes) and rat ( 1,021 genes) (fold-change $>1.5$, significant differences across groups by ANOVA, and $p<0.05$ compared to average gene expression in all other populations in the DRG in the same species). This analysis might be influenced by the fact that the representation of cell population differs in each data set (Fig 1a). Nonetheless this analysis allowed us to compare the three gene sets, 
which revealed 200 genes shared between SGC in human and rodents (Fig. 3a, Supplementary Table 1). The common genes included FABP7, ApoE, FASN, Kir4.1, and Gja1, suggesting conserved roles of SGC related to lipid metabolism (FABP7, ApoE and Fasn), physiological properties (Kir4.1) and cell-cell communication (Gja1/Cx43). Many of the shared genes were also expressed in astrocytes (Supplementary fig. 2a), consistent with our previous findings that $10 \%$ of top enriched genes in mouse SGC were shared between with brain astrocytes (Avraham, Deng, et al., 2020). We next examined if human SGC also share their unique expressed genes with human mature and fetal astrocytes (Zhang et al., 2016). We found that human SGC share 188 genes with human mature astrocytes, 119 genes with human fetal astrocytes and 237 genes were shared with both mature and fetal astrocytes (Supplementary fig. 2a, supplementary table 2). Despite the diversity in morphology and signaling mechanisms between astrocytes and SGC, these results support that important parallels between these two cells are conserved in human.

We next compared human SGC to the other main types of glial cells in the peripheral nervous system Schwann cells. Schwann cells (SC) are divided to two types; myelinating (mySC) and non-myelinating (nmSC). We identified both types of SC in our human scRNAseq data set and compared their similarity to SGC. We found that human SGC share 587 genes with nmSC, 516 genes with mySC and 324 genes with both mySC and nmSC (Supplementary fig. 2b, supplementary table 3). Comparison of SC types between human and mouse (Wolbert et al., 2020) showed more similarity between mouse mySC and human mySC and nmSC (Supplementary fig. 2c, supplementary table 4). Our recent work also identified that mouse SGC do not represent a uniform cell population and at least four subtypes exist (Avraham, Feng, et al., 2020). One of the sublcuster (mSGC3) we defined showed the highest similarity to astrocytes and another subcluster (mSGC 4) resembled the most to mySC (Avraham, Feng, et al., 2020). We did not detect human SGC subclusters in our human data set, possibly because the number of SCG cells was not sufficient. However, we found that human SGC expressed a unique gene set that showed the highest similarity to the mSGC3, which shares the most genes with astrocytes 
(Supplementary fig. 2d, supplementary table 5). These results further support the high similarity at the gene expression level between SGC and astrocytes and extend this similarity to human tissue.

We next analyzed the enriched biological pathways using KEGG 2016 (Kyoto Encyclopedia of Genes and Genomes) and Gene Ontoloty (GO). We found that rodents SGC show enriched molecular functions (GO MF) related to enzymatic activity and cell adhesion, whereas human SGC were enriched in enzymatic activity as well as ion channel and transport activity (Fig. 3b-d). Both rodents and human SGC shared some cellular components (GO CC), including cell junction and projection, involvement in plasma membrane and synaptic activity (Fig. 3b-d). The biological process enriched pathways (GO BP) in human and rodents were particularly similar, with enrichment for mainly metabolic pathways of lipids and cholesterol, as well as processes related to nervous system development (Fig. 3b-d). We previously revealed that fatty acid synthesis and PPARa signaling pathway were enriched in mouse SGC and those pathways were also upregulated after peripheral nerve injury in SGC (Avraham, Deng, et al., 2020). We demonstrated that PPARa activity downstream of fatty acid synthesis in SGC contributes to promote axon regeneration in adult peripheral nerves (Avraham, Deng, et al., 2020). Pathway analysis using KEGG demonstrated lipid metabolic pathways such as fatty acid and steroid metabolism along with PPAR signaling pathway as the top enriched pathway in all species (Fig. 3b-d). These observations further confirm the similarity between human and rodent SGC and suggest that SGC might contribute to nerve regeneration also in humans.

\section{Human SGC express a variety of ion channels and receptors}

Astrocytes influence neural activity, in part by controlling the neuronal microenvironment through maintaining homeostasis of neurotransmitters, potassium buffering, and synaptic transmission. SGC express potassium channels and glutamate transporters, suggesting that they perform similar functions in the PNS. However, the exact composition of ion channels and 
receptors in SGC is not well characterized. Pathway analysis of unique gene set in human SGC demonstrated an enrichment in ion channel function, specifically ion transport activity (Fig. 3d). We found 60 unique ion channel and receptors expressed in human SGC, with 16 of them in the top expressed genes in SGC (>100,000 normalized total counts, Table 2), 40 genes in mouse and 18 genes in rat (Fig. 4a). A majority of genes were related to potassium channels and glutamate receptors in both human and rodents (Fig. 4b). All species shared 4 genes; Kir4.1/Kcnj10, Gja1/Cx43, Grid2 (Glutamate Ionotropic Receptor Delta Type Subunit 2) and Aqp4 (Aquaporin-4) (Fig. 4a). While the potassium channel Kir4.1 and the Gap junction Cx43 were previously reported as rodent SGC marker genes, Grid2 and Aqp4 were not. Interestingly, the glutamate receptor Grid2 is enriched in fetal human astrocytes but not in mature astrocytes (Supplementary table 1) (Zhang et al., 2016). Aquaporin-4 is a water channel predominantly found in astrocytes in the central nervous system and is believed to play a critical role in the formation and maintenance of the blood-brain barrier and in water secretion from the brain (Nielsen et al., 1997), further highlighting that the similarity between SGC and astrocytes is conserved in human.

Examination of enriched molecular pathways (KEGG) of the enriched channel and receptor sets in SGC for each species revealed that the top pathways were related to neuroactive ligand-receptor interaction and calcium signaling environmental (Fig. 4c). Mouse and human SGC were also enriched for glutamatergic and dopaminergic synapse (Fig. 4c). A pathway that was solely enriched in human but not in rodent SGC is inflammatory mediator regulation of TRP channels (Fig. 4c). The similarity in ion channel and receptor composition between human and rodent SGC suggests conserved physiological roles of SGC across species.

SGC have been implicated in pain conditions related to viral infection such as herpesvirus, varicella zoster virus and also swine hemagglutinating encephalomyelitis virus, which is related to the coronavirus family (Hanani \& Spray, 2020). Current models suggest that SGC surrounding virally infected neurons may restrict the virus spread (Hanani \& Spray, 2020). A recent work suggested that sensory neurons could be potential targets for the infection of SARS-CoV-2 
(Shiers et al., 2020). COVID-19, the disease caused by the SARS-CoV-2 can trigger many unexplained neurological effects including chronic pain. Price and colleagues found that a subset of human DRG neurons express the SARS-CoV-2 receptor angiotensin-converting enzyme 2 (ACE2) at the RNA and protein level. DRG neurons also express SARS-CoV-2 coronavirusassociated factors and receptors (SCARFs), which were shown to be expressed in DRG at the lumbar and thoracic level as assessed by bulk RNA sequencing of human DRG tissue (Shiers et al., 2020). Having the resolution of single cell in human DRG, we assessed the expression of SCARF genes specifically in SGC. While the ACE2 receptor was lowly expressed in SGC in all three species, the assembly/trafficking factors Rab10 and Rab1a and the restriction factor IFITM3 were highly expressed (Fig. 5a,b). Interferon-induced transmembrane proteins (IFITMs) restricts infections by many viruses, but a subset of IFITMs can enhance infections by specific coronaviruses. Recently, it has been showed that human IFITM3 with mutations in its endocytic motif enhances SARS-CoV-2 Spike-mediated cell-to-cell fusion and thus raised the concept that polymorphisms in IFITM3 can positively or negatively influence COVID-19 severity (Shi et al, 2021). Weather IFITM3 expression in SGC enhance or limit viral infection in sensory ganglia remains to be determined. Together, these results suggest that SARS-CoV-2 may gain access to the nervous system through entry into sensory neurons at free nerve endings in organs and that SGC may attempt to restrict the local diffusion of the virus (Hanani \& Spray, 2020; Y. C. Li et al., 2012).

\section{DISCUSSION}

The biology of SGC has remained poorly characterized under normal or pathological condition. Most of the current knowledge on SGC function stems from studies in rodents. Here we present a direct comparison of transcriptional profile of SGC in mouse, rat and human at the single cell level. Our findings suggest that key features of SGC in rodent models are conserved in human. Our study provides the potential to leverage rodent and human SGC properties and 
unravel novel mechanisms and potential targets for treating nerve injuries and other pathological conditions.

Our previous study demonstrated that SGC contribute to the nerve repair process in mice (Avraham, Deng, et al., 2020) and that the FDA approved PPARa agonist fenofibrate, which is used in dyslipidemia treatment, can increase axon regeneration after the dorsal root injury, a model of poor sensory axon growth (Avraham, Feng, et al., 2020). Fenofibrate was surprisingly shown in clinical trials to have neuroprotective effects in diabetic retinopathy (Bogdanov, Hernandez, Corraliza, Carvalho, \& Simo, 2015; Moreno \& Ceru, 2015) and traumatic brain injury (Chen et al., 2007). Fenofibrate was also shown to exert analgesic and neuroprotective effects in rodent models of chronic neuropathic pain and inflammation as well as in some human studies (Esmaeili et al., 2016; Oliveira et al., 2007; Othman et al., 2015). The neuroprotective role of fenofibrate was also recently observed in a paclitaxel chemotherapy-induced peripheral neuropathy (Caillaud et al., 2021). It is possible that this neuroprotection is mediated by an effect of PPAR $\alpha$ activation in SGC. Together, these studies further support a central role for SGC in multiple pathological conditions affecting peripheral nerves. The observation that PPAR signaling is similarly enriched in human and rodents SGC opens the potential pharmacological repurposing of fenofibrate and that manipulation of SGC could lead to avenues to promote functional recovery after nervous system injuries.

Our study also highlights that the functional similarity of SGC and astrocytes is conserved across species. Both cell types undergo major changes under pathological conditions, which can have a protective function, but can also contribute to disease, and chronic pain (Hanani \& Verkhratsky, 2021). One of the main functional similarities is buffering of extracellular potassium. In the CNS, glial buffering of extracellular potassium is carried out by astrocytes and consists of potassium uptake by inwardly rectifying potassium (Kir) channels (Konishi, 1996). Kir channels are key regulators of glial functions, which in turn determine neuronal excitability and axonal conduction (Butt \& Kalsi, 2006). Functionally, Kir channels can be divided into different subtypes 
based on their biophysical properties. Kir4.1 is an ATP-dependent potassium channel, whereas Kir3.1 is a G protein-activated potassium channel (Butt \& Kalsi, 2006). Most astrocytes express Kir4.1 but rat astrocytes and guinea-pig Muller glia have been shown to express Kir3.1 (Olsen \& Sontheimer, 2004; Raap et al., 2002). Our studies revealed that human SGC preferentially express Kir3.1, mice SGC mainly express Kir4.1 and rat SGC express low level of both Kir channels and more SK3. Nerve damage was shown to downregulate the expression of Kir4.1 (Takeda, Takahashi, Nasu, \& Matsumoto, 2011; Tang, Schmidt, Perez-Leighton, \& Kofuji, 2010; Vit et al., 2008) and silencing Kir4.1 in the rat trigeminal ganglia leads to pain- like behavior (Vit et al., 2008). Similarly, gain or loss of Kir4.1 affects astrocyte ability to regulate neuronal activity (Cui et al., 2018). The diversity in potassium channel expression in SGC might suggest that differences in signaling mechanisms related to ATP or G protein coupled receptors define the physiological characteristics of SGC across species.

We also observed an enrichment for other types of channels in human SGC, including sodium and water channels, chloride channels and TRP channels. Transient receptor potential (TRP) proteins consist of a superfamily of cation channels that have been involved in diverse physiological processes in the brain as well as in the pathogenesis of neurological disease. TRP channels are widely expressed in the brain, including neurons and glial cells. Channels of TRP family have been shown to be involved in sensation and modulation of pain in peripheral ganglia but their expression in SGC have not been demonstrated. TRP channels contribute to the transition of inflammation and immune responses from a defensive early response to a chronic and pathological conditions. The expression of purinergic and glutamate receptor was also highly conserved between human and mice, suggesting that the ATP and glutamate dependent communication between neuron and glia in response to neuronal activity and pathological conditions is largely conserved. Whether different channels are expressed in SGC surrounding different types of sensory neurons remains to be determined. In mice we detected at least 4 SGC subtype with no evidence that one of the subtypes is dedicate to one class of sensory neurons 
(Avraham, Feng, et al., 2020). Spatial transcriptomics approaches or in situ hybridization to molecularly characterize transcriptomes of DRG and their adjacent SGC (Tavares-Ferreira et al., 2021) might shed light on the molecular properties of individual neuron-SGC units in human.

Another main feature common to astrocytes and SGC and conserved across species is the enrichment for genes related to lipid metabolism and expression of ApoE. In astrocyte, lipid metabolism is critical for synapse development and function in vivo (Barres \& Smith, 2001; van Deijk et al., 2017). ApoE is predominantly secreted by astrocytes in the brain and functions as a major transporter of lipoproteins between cells. Of the three ApoE alleles, the ApoE4 allele is associated with an increased risk for Alzheimer's disease (AD) (Long \& Holtzman, 2019). ApoE likely regulates AD risk in large part via effects on amyloid pathology (Leyns \& Holtzman, 2017). However, several studies revealed a role for ApoE in lipid delivery for axon growth (F. Q. Li, Fowler, Neil, Colton, \& Vitek, 2010; Nakato et al., 2015; Vance, Campenot, \& Vance, 2000; Vance, Pan, Campenot, Bussiere, \& Vance, 1994). We previously found that ApoE expression is increased in SGC via activation of the PPAR $\alpha$ signaling after nerve injury (Avraham, Deng, et al., 2020). The pathophysiological changes in AD are believed to arise in part from defects in neuronal communication in the central nervous system (Kamenetz et al., 2003; Sheng, Sabatini, \& Sudhof, 2012). However, decline in different sensory modalities are suggested to be a primary first-tier pathology (Daulatzai, 2016). In cultured sensory neurons, exogenously applied ApoE4 directly inhibits neurite outgrowth, whereas ApoE3 stimulates neurite outgrowth (Nathan et al., 1994). These studies suggest that the ApoE4 risk factors in human SGC may directly impact sensory neurons and potentially hearing dysfunction (Hardy et al., 2016; C. M. Liu \& Lee, 2019; Loughrey, Kelly, Kelley, Brennan, \& Lawlor, 2018; Ralli et al., 2019; Sarant et al., 2020; Swords, Nguyen, Mudar, \& Llano, 2018; Thomson, Auduong, Miller, \& Gurgel, 2017) and postural instability (Belghali, Chastan, Cignetti, Davenne, \& Decker, 2017; Lee, Lee, Chung, \& Yi, 2017), which have been associated with neurodegenerative disorders such as Alzheimer's disease (AD) and agerelated dementia in humans. 


\section{ACKNOWLEDGEMENTS}

This research was funded by in part by a post-doctoral fellowship from The McDonnell Center for Cellular and Molecular Neurobiology to O.A, by NIH grant NS042595 to R.G, by The McDonnell Center for Cellular and Molecular Neurobiology to V.C., by a Pilot Project Award from the Hope Center for Neurological Disorders at Washington University to V.C. and by NIH grants NS111719 and NS115492 to V.C.

\section{CONFLICTS OF INTEREST}

The authors declare no conflict of interest

\section{DATA AVAILABILITY}

The raw Fastq files and the processed filtered count matrix for scRNA sequencing were deposited at the NCBI GEO database under the accession number GSE158892, GSE169301. Data analysis and processing was performed using commercial code from Partek Flow package at https://www.partek.com/partek-flow/.

\section{AUTHOR CONTRIBUTIONS}

O.A and V.C designed research and wrote the manuscript. O.A. performed mouse and rat single cell sequencing, bioinformatic analyses, immunofluorescence experiments and analyzed data. A.C. performed human single nucleus sequencing. R.F performed bioinformatic analyses and analyzed data. A.H collected rat DRG for single cell sequencing. A.M.M, R.W.G and V.C. supervised the project. All authors edited and approved the manuscript.

\section{REFERENCES}


Avraham, O., Deng, P. Y., Jones, S., Kuruvilla, R., Semenkovich, C. F., Klyachko, A. K., \& Cavalli, V. (2020). Satellite glial cells promote regenerative growth in sensory neurons. Nature Communications, volume 11, Article number: 4891 (2020)

Avraham, O., Feng, R., Ewan, E. E., Zhao, G., \& Cavalli, V. (2020). Profiling sensory neuron microenvironment after peripheral and central axon injury reveals key pathways for neural repair. BiorXiv, https://doi.org/10.1101/2020.11.25.398537

Barres, B. A., \& Smith, S. J. (2001). Neurobiology. Cholesterol--making or breaking the synapse. Science, 294(5545), 1296-1297. doi:10.1126/science.1066724

Belghali, M., Chastan, N., Cignetti, F., Davenne, D., \& Decker, L. M. (2017). Loss of gait control assessed by cognitive-motor dual-tasks: pros and cons in detecting people at risk of developing Alzheimer's and Parkinson's diseases. Geroscience, 39(3), 305-329. doi:10.1007/s11357-017-9977-7

Bogdanov, P., Hernandez, C., Corraliza, L., Carvalho, A. R., \& Simo, R. (2015). Effect of fenofibrate on retinal neurodegeneration in an experimental model of type 2 diabetes. Acta Diabetol, 52(1), 113-122. doi:10.1007/s00592-014-0610-2

Butt, A. M., \& Kalsi, A. (2006). Inwardly rectifying potassium channels (Kir) in central nervous system glia: a special role for Kir4.1 in glial functions. J Cell Mol Med, 10(1), 33-44. doi:10.1111/j.1582-4934.2006.tb00289.x

Caillaud, M., Patel, N. H., White, A., Wood, M., Contreras, K. M., Toma, W., . . Imad Damaj, M. (2021). Targeting Peroxisome Proliferator-Activated Receptor-alpha (PPAR-alpha) to Reduce Paclitaxel-Induced Peripheral Neuropathy. Brain Behav Immun. doi:10.1016/j.bbi.2021.01.004

Carozzi, V. A., Canta, A., Oggioni, N., Sala, B., Chiorazzi, A., Meregalli, C., . . Cavaletti, G. (2010). Neurophysiological and neuropathological characterization of new murine models of chemotherapy-induced chronic peripheral neuropathies. Exp Neurol, 226(2), 301-309. doi:10.1016/j.expneurol.2010.09.004

Carozzi, V. A., Renn, C. L., Bardini, M., Fazio, G., Chiorazzi, A., Meregalli, C., . . Dorsey, S. G. (2013). Bortezomib-induced painful peripheral neuropathy: an electrophysiological, behavioral, morphological and mechanistic study in the mouse. PLoS One, 8(9), e72995. doi:10.1371/journal.pone.0072995

Chen, X. R., Besson, V. C., Palmier, B., Garcia, Y., Plotkine, M., \& Marchand-Leroux, C. (2007). Neurological recovery-promoting, anti-inflammatory, and anti-oxidative effects afforded by fenofibrate, a PPAR alpha agonist, in traumatic brain injury. J Neurotrauma, 24(7), 1119-1131. doi:10.1089/neu.2006.0216

Cherkas, P. S., Huang, T. Y., Pannicke, T., Tal, M., Reichenbach, A., \& Hanani, M. (2004). The effects of axotomy on neurons and satellite glial cells in mouse trigeminal ganglion. Pain, 110(1-2), 290-298. doi:10.1016/j.pain.2004.04.007

Christie, K., Koshy, D., Cheng, C., Guo, G., Martinez, J. A., Duraikannu, A., \& Zochodne, D. W. (2015). Intraganglionic interactions between satellite cells and adult sensory neurons. Mol Cell Neurosci, 67, 1-12. doi:10.1016/j.mcn.2015.05.001

Cui, Y., Yang, Y., Ni, Z., Dong, Y., Cai, G., Foncelle, A., .. . Hu, H. (2018). Astroglial Kir4.1 in the lateral habenula drives neuronal bursts in depression. Nature, 554(7692), 323-327. doi:10.1038/nature25752 
Daulatzai, M. A. (2016). Dysfunctional Sensory Modalities, Locus Coeruleus, and Basal Forebrain: Early Determinants that Promote Neuropathogenesis of Cognitive and Memory Decline and Alzheimer's Disease. Neurotox Res, 30(3), 295-337. doi:10.1007/s12640-016-9643-3

Davidson, S., Copits, B. A., Zhang, J., Page, G., Ghetti, A., \& Gereau, R. W. (2014). Human sensory neurons: Membrane properties and sensitization by inflammatory mediators. Pain, 155(9), 1861-1870. doi:10.1016/j.pain.2014.06.017

Dean, J. M., \& Lodhi, I. J. (2018). Structural and functional roles of ether lipids. Protein Cell, 9(2), 196-206. doi:10.1007/s13238-017-0423-5

Donegan, M., Kernisant, M., Cua, C., Jasmin, L., \& Ohara, P. T. (2013). Satellite glial cell proliferation in the trigeminal ganglia after chronic constriction injury of the infraorbital nerve. Glia, 61(12), 2000-2008. doi:10.1002/glia.22571

Esmaeili, M. A., Yadav, S., Gupta, R. K., Waggoner, G. R., Deloach, A., Calingasan, N. Y., . . Kiaei, M. (2016). Preferential PPAR-alpha activation reduces neuroinflammation, and blocks neurodegeneration in vivo. Hum Mol Genet, 25(2), 317-327. doi:10.1093/hmg/ddv477

Fatahzadeh, M., \& Schwartz, R. A. (2007). Human herpes simplex virus infections: epidemiology, pathogenesis, symptomatology, diagnosis, and management. J Am Acad Dermatol, 57(5), 737-763; quiz 764-736. doi:10.1016/j.jaad.2007.06.027

Fenzi, F., Benedetti, M. D., Moretto, G., \& Rizzuto, N. (2001). Glial cell and macrophage reactions in rat spinal ganglion after peripheral nerve lesions: an immunocytochemical and morphometric study. Arch Ital Biol, 139(4), 357-365.

George, D., Ahrens, P., \& Lambert, S. (2018). Satellite glial cells represent a population of developmentally arrested Schwann cells. Glia. doi:10.1002/glia.23320

Habib, N., Avraham-Davidi, I., Basu, A., Burks, T., Shekhar, K., Hofree, M., . . Regev, A. (2017). Massively parallel single-nucleus RNA-seq with DroNc-seq. Nat Methods, 14(10), $955-$ 958. doi:10.1038/nmeth.4407

Hanani, M. (2005). Satellite glial cells in sensory ganglia: from form to function. Brain Res Brain Res Rev, 48(3), 457-476. doi:10.1016/j.brainresrev.2004.09.001

Hanani, M., Huang, T. Y., Cherkas, P. S., Ledda, M., \& Pannese, E. (2002). Glial cell plasticity in sensory ganglia induced by nerve damage. Neuroscience, 114(2), 279-283.

Hanani, M., \& Spray, D. C. (2020). Emerging importance of satellite glia in nervous system function and dysfunction. Nat Rev Neurosci, 21(9), 485-498. doi:10.1038/s41583-0200333-z

Hanani, M., \& Verkhratsky, A. (2021). Satellite Glial Cells and Astrocytes, a Comparative Review. Neurochem Res. doi:10.1007/s11064-021-03255-8

Hardy, C. J., Marshall, C. R., Golden, H. L., Clark, C. N., Mummery, C. J., Griffiths, T. D., .. . Warren, J. D. (2016). Hearing and dementia. J Neurol, 263(11), 2339-2354. doi:10.1007/s00415-016-8208-y

Huang, L. Y., Gu, Y., \& Chen, Y. (2013). Communication between neuronal somata and satellite glial cells in sensory ganglia. Glia, 61(10), 1571-1581. doi:10.1002/glia.22541

Huang, T. Y., Cherkas, P. S., Rosenthal, D. W., \& Hanani, M. (2005). Dye coupling among satellite glial cells in mammalian dorsal root ganglia. Brain Res, 1036(1-2), 42-49.

doi:10.1016/j.brainres.2004.12.021 
Jager, S. B., Pallesen, L. T., \& Vaegter, C. B. (2018). Isolation of satellite glial cells for high-quality RNA purification. J Neurosci Methods, 297, 1-8. doi:10.1016/j.jneumeth.2018.01.001

Jager, S. E., Pallesen, L. T., Richner, M., Harley, P., Hore, Z., McMahon, S., . . Vaegter, C. B. (2020). Changes in the transcriptional fingerprint of satellite glial cells following peripheral nerve injury. Glia. doi:10.1002/glia.23785

Kamenetz, F., Tomita, T., Hsieh, H., Seabrook, G., Borchelt, D., Iwatsubo, T., . . Malinow, R. (2003). APP processing and synaptic function. Neuron, 37(6), 925-937.

Koeppen, A. H., Becker, A. B., Qian, J., \& Feustel, P. J. (2017). Friedreich Ataxia: Hypoplasia of Spinal Cord and Dorsal Root Ganglia. J Neuropathol Exp Neurol, 76(2), 101-108. doi:10.1093/jnen/nlw111

Koeppen, A. H., Ramirez, R. L., Becker, A. B., \& Mazurkiewicz, J. E. (2016). Dorsal root ganglia in Friedreich ataxia: satellite cell proliferation and inflammation. Acta Neuropathol Commun, 4(1), 46. doi:10.1186/s40478-016-0288-5

Konishi, T. (1996). Developmental and activity-dependent changes in K+ currents in satellite glial cells in mouse superior cervical ganglion. Brain Res, 708(1-2), 7-15. doi:10.1016/0006-8993(95)01221-4

Kung, L. H., Gong, K., Adedoyin, M., Ng, J., Bhargava, A., Ohara, P. T., \& Jasmin, L. (2013). Evidence for glutamate as a neuroglial transmitter within sensory ganglia. PLoS One, 8(7), e68312. doi:10.1371/journal.pone.0068312

Lang, B. T., Cregg, J. M., DePaul, M. A., Tran, A. P., Xu, K., Dyck, S. M., . . Silver, J. (2015). Modulation of the proteoglycan receptor PTPsigma promotes recovery after spinal cord injury. Nature, 518(7539), 404-408. doi:10.1038/nature13974

Ledda, M., De Palo, S., \& Pannese, E. (2004). Ratios between number of neuroglial cells and number and volume of nerve cells in the spinal ganglia of two species of reptiles and three species of mammals. Tissue Cell, 36(1), 55-62.

Lee, Y. W., Lee, H., Chung, I. S., \& Yi, H. A. (2017). Relationship between postural instability and subcortical volume loss in Alzheimer's disease. Medicine (Baltimore), 96(25), e7286. doi:10.1097/MD.0000000000007286

Leyns, C. E. G., \& Holtzman, D. M. (2017). Glial contributions to neurodegeneration in tauopathies. Mol Neurodegener, 12(1), 50. doi:10.1186/s13024-017-0192-x

Li, F. Q., Fowler, K. A., Neil, J. E., Colton, C. A., \& Vitek, M. P. (2010). An apolipoprotein Emimetic stimulates axonal regeneration and remyelination after peripheral nerve injury. J Pharmacol Exp Ther, 334(1), 106-115. doi:10.1124/jpet.110.167882

Li, Y. C., Bai, W. Z., Hirano, N., Hayashida, T., \& Hashikawa, T. (2012). Coronavirus infection of rat dorsal root ganglia: ultrastructural characterization of viral replication, transfer, and the early response of satellite cells. Virus Res, 163(2), 628-635.

doi:10.1016/j.virusres.2011.12.021

Lindborg, J. A., Niemi, J. P., Howarth, M. A., Liu, K. W., Moore, C. Z., Mahajan, D., \& Zigmond, R. E. (2018). Molecular and cellular identification of the immune response in peripheral ganglia following nerve injury. J Neuroinflammation, 15(1), 192. doi:10.1186/s12974018-1222-5

Liu, C. M., \& Lee, C. T. (2019). Association of Hearing Loss With Dementia. JAMA Netw Open, 2(7), e198112. doi:10.1001/jamanetworkopen.2019.8112 
Liu, F. Y., Sun, Y. N., Wang, F. T., Li, Q., Su, L., Zhao, Z. F., .. . Wan, Y. (2012). Activation of satellite glial cells in lumbar dorsal root ganglia contributes to neuropathic pain after spinal nerve ligation. Brain Res, 1427, 65-77. doi:10.1016/j.brainres.2011.10.016

Long, J. M., \& Holtzman, D. M. (2019). Alzheimer Disease: An Update on Pathobiology and Treatment Strategies. Cell, 179(2), 312-339. doi:10.1016/j.cell.2019.09.001

Loughrey, D. G., Kelly, M. E., Kelley, G. A., Brennan, S., \& Lawlor, B. A. (2018). Association of Age-Related Hearing Loss With Cognitive Function, Cognitive Impairment, and Dementia: A Systematic Review and Meta-analysis. JAMA Otolaryngol Head Neck Surg, 144(2), 115-126. doi:10.1001/jamaoto.2017.2513

Mangus, L. M., Weinberg, R. L., Knight, A. C., Queen, S. E., Adams, R. J., \& Mankowski, J. L. (2019). SIV-Induced Immune Activation and Metabolic Alterations in the Dorsal Root Ganglia During Acute Infection. J Neuropathol Exp Neurol, 78(1), 78-87. doi:10.1093/jnen/nly111

Martelotto, L. G., \& Martelotto, L. (2020). 'Frankenstein' protocol for nuclei isolation from fresh and frozen tissue for snRNAseq V.2 protocols.io, https://dx.doi.org/10.17504/protocols.io.3fkgjkw.

Martinelli, C., Sartori, P., De Palo, S., Ledda, M., \& Pannese, E. (2006). The perineuronal glial tissue of spinal ganglia. Quantitative changes in the rabbit from youth to extremely advanced age. Anat Embryol (Berl), 211(5), 455-463. doi:10.1007/s00429-006-0097-x

Michalowsky, B., Hoffmann, W., \& Kostev, K. (2019). Association Between Hearing and Vision Impairment and Risk of Dementia: Results of a Case-Control Study Based on Secondary Data. Front Aging Neurosci, 11, 363. doi:10.3389/fnagi.2019.00363

Miller, K. E., Richards, B. A., \& Kriebel, R. M. (2002). Glutamine-, glutamine synthetase-, glutamate dehydrogenase- and pyruvate carboxylase-immunoreactivities in the rat dorsal root ganglion and peripheral nerve. Brain Res, 945(2), 202-211.

Moreno, S., \& Ceru, M. P. (2015). In search for novel strategies towards neuroprotection and neuroregeneration: is PPARalpha a promising therapeutic target? Neural Regen Res, 10(9), 1409-1412. doi:10.4103/1673-5374.165313

Nakato, M., Matsuo, M., Kono, N., Arita, M., Arai, H., Ogawa, J., . . Ueda, K. (2015). Neurite outgrowth stimulation by $n-3$ and n-6 PUFAs of phospholipids in apoE-containing lipoproteins secreted from glial cells. J Lipid Res, 56(10), 1880-1890. doi:10.1194/jlr.M058164

Nathan, B. P., Bellosta, S., Sanan, D. A., Weisgraber, K. H., Mahley, R. W., \& Pitas, R. E. (1994). Differential effects of apolipoproteins E3 and E4 on neuronal growth in vitro. Science, 264(5160), 850-852. doi:10.1126/science.8171342

Nielsen, S., Nagelhus, E. A., Amiry-Moghaddam, M., Bourque, C., Agre, P., \& Ottersen, O. P. (1997). Specialized membrane domains for water transport in glial cells: high-resolution immunogold cytochemistry of aquaporin-4 in rat brain. J Neurosci, 17(1), 171-180.

North, R. Y., Li, Y., Ray, P., Rhines, L. D., Tatsui, C. E., Rao, G., .. Dougherty, P. M. (2019). Electrophysiological and transcriptomic correlates of neuropathic pain in human dorsal root ganglion neurons. Brain, 142(5), 1215-1226. doi:10.1093/brain/awz063

Oliveira, A. C., Bertollo, C. M., Rocha, L. T., Nascimento, E. B., Jr., Costa, K. A., \& Coelho, M. M. (2007). Antinociceptive and antiedematogenic activities of fenofibrate, an agonist of 
PPAR alpha, and pioglitazone, an agonist of PPAR gamma. Eur J Pharmacol, 561(1-3), 194-201. doi:10.1016/j.ejphar.2006.12.026

Olsen, M. L., \& Sontheimer, H. (2004). Mislocalization of Kir channels in malignant glia. Glia, 46(1), 63-73. doi:10.1002/glia.10346

Othman, A., Benghozi, R., Alecu, I., Wei, Y., Niesor, E., von Eckardstein, A., \& Hornemann, T. (2015). Fenofibrate lowers atypical sphingolipids in plasma of dyslipidemic patients: A novel approach for treating diabetic neuropathy? J Clin Lipidol, 9(4), 568-575. doi:10.1016/j.jacl.2015.03.011

Pannese, E. (1964). Number and Structure of Perisomatic Satellite Cells of Spinal Ganglia under Normal Conditions or during Axon Regeneration and Neuronal Hypertrophy. Z Zellforsch Mikrosk Anat, 63, 568-592.

Pannese, E. (1981). The satellite cells of the sensory ganglia. Adv Anat Embryol Cell Biol, 65, 1111.

Pannese, E. (2002). Perikaryal surface specializations of neurons in sensory ganglia. Int Rev Cytol, 220, 1-34.

Pannese, E. (2010). The structure of the perineuronal sheath of satellite glial cells (SGCs) in sensory ganglia. Neuron Glia Biol, 6(1), 3-10. doi:10.1017/S1740925X10000037

Raap, M., Biedermann, B., Braun, P., Milenkovic, I., Skatchkov, S. N., Bringmann, A., \& Reichenbach, A. (2002). Diversity of Kir channel subunit mRNA expressed by retinal glial cells of the guinea-pig. Neuroreport, 13(8), 1037-1040. doi:10.1097/00001756200206120-00012

Ralli, M., Gilardi, A., Stadio, A. D., Severini, C., Salzano, F. A., Greco, A., \& Vincentiis, M. (2019). Hearing loss and Alzheimer's disease: A Review. Int Tinnitus J, 23(2), 79-85. doi:10.5935/0946-5448.20190014

Rostock, C., Schrenk-Siemens, K., Pohle, J., \& Siemens, J. (2017). Human vs. Mouse Nociceptors - Similarities and Differences. Neuroscience. doi:10.1016/j.neuroscience.2017.11.047

Sarant, J., Harris, D., Busby, P., Maruff, P., Schembri, A., Lemke, U., \& Launer, S. (2020). The Effect of Hearing Aid Use on Cognition in Older Adults: Can We Delay Decline or Even Improve Cognitive Function? J Clin Med, 9(1). doi:10.3390/jcm9010254

Sheng, M., Sabatini, B. L., \& Sudhof, T. C. (2012). Synapses and Alzheimer's disease. Cold Spring Harb Perspect Biol, 4(5). doi:cshperspect.a005777 [pii]

10.1101/cshperspect.a005777

Shiers, S., Ray, P. R., Wangzhou, A., Sankaranarayanan, I., Tatsui, C. E., Rhines, L. D., ... Price, T. J. (2020). ACE2 and SCARF expression in human dorsal root ganglion nociceptors: implications for SARS-CoV-2 virus neurological effects. Pain, 161(11), 2494-2501. doi:10.1097/j.pain.0000000000002051

Slyper, M., Porter, C. B. M., Ashenberg, O., Waldman, J., Drokhlyansky, E., Wakiro, I., ... Regev, A. (2020). A single-cell and single-nucleus RNA-Seq toolbox for fresh and frozen human tumors. Nat Med, 26(5), 792-802. doi:10.1038/s41591-020-0844-1

Spray, D. C., Iglesias, R., Shraer, N., Suadicani, S. O., Belzer, V., Hanstein, R., \& Hanani, M. (2019). Gap junction mediated signaling between satellite glia and neurons in trigeminal ganglia. Glia, 67(5), 791-801. doi:10.1002/glia.23554 
Swords, G. M., Nguyen, L. T., Mudar, R. A., \& Llano, D. A. (2018). Auditory system dysfunction in Alzheimer disease and its prodromal states: A review. Ageing Res Rev, 44, 49-59. doi:10.1016/j.arr.2018.04.001

Takahashi, M., \& Osumi, N. (2005). Identification of a novel type II classical cadherin: rat cadherin19 is expressed in the cranial ganglia and Schwann cell precursors during development. Dev Dyn, 232(1), 200-208. doi:10.1002/dvdy.20209

Takeda, M., Takahashi, M., Nasu, M., \& Matsumoto, S. (2011). Peripheral inflammation suppresses inward rectifying potassium currents of satellite glial cells in the trigeminal ganglia. Pain, 152(9), 2147-2156. doi:10.1016/j.pain.2011.05.023

Tang, X., Schmidt, T. M., Perez-Leighton, C. E., \& Kofuji, P. (2010). Inwardly rectifying potassium channel Kir4.1 is responsible for the native inward potassium conductance of satellite glial cells in sensory ganglia. Neuroscience, 166(2), 397-407. doi:10.1016/j.neuroscience.2010.01.005

Tavares-Ferreira, D., Shiers, S., Ray, P., Wangzhou, A., Jeevakumar, V., Sankaranarayanan, I., . . . Price, T. J. (2021). Spatial transcriptomics reveals unique molecular fingerprints of human nociceptors. BiorXiv, https://doi.org/10.1101/2021.02.06.430065;

Thomson, R. S., Auduong, P., Miller, A. T., \& Gurgel, R. K. (2017). Hearing loss as a risk factor for dementia: A systematic review. Laryngoscope Investig Otolaryngol, 2(2), 69-79. doi:10.1002/lio2.65

Valtcheva, M. V., Copits, B. A., Davidson, S., Sheahan, T. D., Pullen, M. Y., McCall, J. G., . . . Gereau, R. W. t. (2016). Surgical extraction of human dorsal root ganglia from organ donors and preparation of primary sensory neuron cultures. Nat Protoc, 11(10), 18771888. doi:10.1038/nprot.2016.111

van Deijk, A. F., Camargo, N., Timmerman, J., Heistek, T., Brouwers, J. F., Mogavero, F., . . . Verheijen, M. H. (2017). Astrocyte lipid metabolism is critical for synapse development and function in vivo. Glia, 65(4), 670-682. doi:10.1002/glia.23120

Vance, J. E., Campenot, R. B., \& Vance, D. E. (2000). The synthesis and transport of lipids for axonal growth and nerve regeneration. Biochim Biophys Acta, 1486(1), 84-96.

Vance, J. E., Pan, D., Campenot, R. B., Bussiere, M., \& Vance, D. E. (1994). Evidence that the major membrane lipids, except cholesterol, are made in axons of cultured rat sympathetic neurons. J Neurochem, 62(1), 329-337.

Vit, J. P., Ohara, P. T., Bhargava, A., Kelley, K., \& Jasmin, L. (2008). Silencing the Kir4.1 potassium channel subunit in satellite glial cells of the rat trigeminal ganglion results in pain-like behavior in the absence of nerve injury. J Neurosci, 28(16), 4161-4171. doi:10.1523/JNEUROSCI.5053-07.2008

Warwick, R. A., \& Hanani, M. (2013). The contribution of satellite glial cells to chemotherapyinduced neuropathic pain. Eur J Pain, 17(4), 571-580. doi:10.1002/j.15322149.2012.00219.x

Wolbert, J., Li, X., Heming, M., Mausberg, A. K., Akkermann, D., Frydrychowicz, C., . . Meyer Zu Horste, G. (2020). Redefining the heterogeneity of peripheral nerve cells in health and autoimmunity. Proc Natl Acad Sci U S A. doi:10.1073/pnas.1912139117

Woodham, P., Anderson, P. N., Nadim, W., \& Turmaine, M. (1989). Satellite cells surrounding axotomised rat dorsal root ganglion cells increase expression of a GFAP-like protein. Neurosci Lett, 98(1), 8-12. doi:10.1016/0304-3940(89)90364-9 
Zerboni, L., Ku, C. C., Jones, C. D., Zehnder, J. L., \& Arvin, A. M. (2005). Varicella-zoster virus infection of human dorsal root ganglia in vivo. Proc Natl Acad Sci U S A, 102(18), 64906495. doi:10.1073/pnas.0501045102

Zhang, Y., Sloan, S. A., Clarke, L. E., Caneda, C., Plaza, C. A., Blumenthal, P. D., . . Barres, B. A. (2016). Purification and Characterization of Progenitor and Mature Human Astrocytes Reveals Transcriptional and Functional Differences with Mouse. Neuron, 89(1), 37-53. doi:10.1016/j.neuron.2015.11.013 


\section{FIGURE LEGENDS}

Figure 1: Profiling DRG cells from mouse, rat and human

(a) t-SNE plot of human, mouse and rat DRG cells colored by cell populations with fraction of distribution (b) t-SNE overlay for expression of the SGC marker gene Fabp7 in human, mouse and rat (c and d) Representative images of immunofluorescence staining of human (c) and mouse (d) DRG sections labelled with TUJ1 (magenta) and FABP7 (green) Scale bar: $200 \mu$ m (left panel) $50 \mu \mathrm{m}$ (right panel). $\mathrm{n}=4$ biological independent replicates

\section{Figure 2: SGC marker genes in mouse, rat and human}

(a) t-SNE overlay for expression of SGC marker genes Fabp7, Cadh19, GS/Glul and Kir4.1/Kcnj10 in human (b) t-SNE overlay for expression of SGC marker genes in mouse (c) tSNE overlay for expression of SGC marker genes in rat (d) Bubble plot showing the expression of SGC marker genes in each species. Dot size represent the percentage of cells that express the corresponding genes and the color represent the expression mean level (e and $f$ ) Representative images of immunofluorescence staining of human (e) and mouse (f) DRG

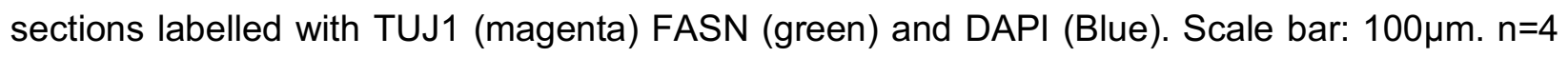
biological independent replicates

Figure 3: Enrichment of genes in mouse, rat and human SGC

(a) Venn diagram for enriched genes in SGC compared to other cells in the DRG from mouse, rat and human. (b) Pathway analysis (KEGG/GO) of enriched genes express in rat SGC. (c)pathway analysis (KEGG/GO) of enriched genes express in mouse SGC. (d) Pathway analysis (KEGG/GO) of enriched genes express in human SGC. 
Figure 4: Enrichment of ion channels and receptors in mouse, rat and human SGC

(a) Venn diagram for enriched ion channel and receptors genes in SGC from mouse, rat and human. (b) Enriched ion channels and receptors in SGC compared to other cell types in the DRG (ANOVA fold change threshold >1.5). (c) Pathway analysis (KEGG 2019) of enriched ion channels and receptors express in mouse, rat and human SGC.

\section{Figure 5: Enrichment of SCARF genes in SGC}

(a) Bubble plot showing the expression of SCARF genes in each SGC in each species. Dot size represent the percentage of cells expressing the corresponding gene and the color represents the expression mean level. (b) t-SNE overlay for co-expression of selected SCARF genes in SGC across species.

\section{TABLES}

\section{Table 1}

Top 10 differentially expressed genes in each cell population compared to all other cell types in the DRG (ANOVA fold change threshold >1.5)

\section{Table 2}

Top expressed ion channels and receptors genes in human SGC

\section{SUPPLEMENTRAY FIGURES}

Supplementary Figure 1: Cell populations marker genes in human, mouse and rat DRG cells

(a) t-SNE overlay for expression of cell population marker genes in human (b) mouse (c) rat.

\section{Supplementary Figure: 2 Similarity of human SGC to Astrocytes and SC}


(a)Venn diagram for genes enriched in human SGC, mature and fetal Astrocytes (b) Enriched human SGC genes compared to human mySC and nmSC (c) Enriched human mySC and nmSC compared to mouse mySC and nmSC (d) Enriched human SGC compared to subclusters of mouse SGC

\section{SUPPLEMENTRAY TABLES}

\section{Supplementary Table 1}

Genes enriched in human, mouse and rat SGC (compared to all other cell types in the DRG (ANOVA fold change threshold >1.5)

\section{Supplementary Table 2}

Genes enriched in human SGC, mature and fetal Astrocytes

\section{Supplementary Table 3}

Genes enriched in human SGC, mySC and nmSC

\section{Supplementary Table 4}

Genes enriched in human and mouse mySC and nmSC

\section{Supplementary Table 5}

Genes enriched in subclusters of mouse SGC 
Table 1: Top 10 differentially expressed genes in each cell population

Human

\begin{tabular}{|c|c|c|c|c|c|c|c|c|c|}
\hline $\begin{array}{c}\text { Top } \\
\text { genes }\end{array}$ & $\begin{array}{c}\text { Connective } \\
\text { Tissue }\end{array}$ & Endothelial & Macrophages & Mesenchymal & $\begin{array}{c}\text { Smooth } \\
\text { Muscle }\end{array}$ & nmSC & mySC & SGC & T-cells \\
\hline 1 & EYA1 & FLT1 & FAM177B & RP11-60A8.1 & FHL5 & NRXN1 & SLC25A48 & GPR98 & BCL11B \\
\hline 2 & PRDM6 & ANO2 & CD86 & EBF2 & $\begin{array}{c}\text { RP11- } \\
39404.6\end{array}$ & GAP43 & MLIP & $\begin{array}{c}\text { RP11- } \\
1220 K 2.2\end{array}$ & THEMIS \\
\hline 3 & CACNA2D3 & ELTD1 & IGSF21 & SHISA6 & MYOCD & AC129778.1 & SLC36A2 & ZNF804B & ITK \\
\hline 4 & THSD4 & TLL1 & FGD2 & VIT & MRV11 & ITGB8 & $\begin{array}{c}\text { RP11- } \\
\text { I36D10.3 }\end{array}$ & CTNND2 & CD2 \\
\hline 5 & POU6F2 & PKHD1L1 & CD163 & ANGPTL7 & MIR145 & NTM & BCAS1 & TRDN & LCK \\
\hline 6 & NPNT & BTNL9 & ADAM28 & AC005237.4 & LDB3 & TMEM132B & DRP2 & QRFPR & DTHD1 \\
\hline 7 & SLC47A1 & POSTN & SYK & SLC22A3 & MIR143HG & IL34 & CDH7 & RIMS1 & SKAP1 \\
\hline 8 & KCNMA1 & EMCN & SLC11A1 & GPC3 & DGKG & FRMD5 & ANKRD30B & $\begin{array}{c}\text { RP11- } \\
532 N 4.2\end{array}$ & IL7R \\
\hline 9 & CACNB2 & PTPRB & $\begin{array}{c}\text { RP11- } \\
\text { I42C4.6 }\end{array}$ & RGS6 & PARM1 & DOK6 & MPZ & SHANK2 & SCML4 \\
\hline 10 & FBLN1 & VEGFC & TRPM2 & CLDN1 & CACNA1H & ST6GALNAC5 & PRX & MMD2 & CD96 \\
\hline
\end{tabular}

Mouse

\begin{tabular}{|c|c|c|c|c|c|c|c|c|c|c|}
\hline $\begin{array}{c}\text { Top } \\
\text { genes }\end{array}$ & $\begin{array}{c}\text { Connective } \\
\text { Tissue }\end{array}$ & Endothelial & Macrophages & Mesenchymal & Neurons & Pericytes & $\begin{array}{c}\text { Schwann } \\
\text { cells }\end{array}$ & sGC & $\begin{array}{c}\text { Smooth } \\
\text { Muscle }\end{array}$ & T-cells \\
\hline 1 & SAA1 & CLDN5 & LY86 & MFAP4 & GAL & KCNJ8 & NCMAP & FABP7 & PLN & CAMP \\
\hline 2 & SAA2 & LY6C1 & PF4 & SFRP4 & TAC1 & ACE2 & SLC36A2 & BCAN & FBXL22 & NGP \\
\hline 3 & CDKN2A & SOX17 & CCL12 & SLC47A1 & PRPH & ADRA2A & FAM178B & $\begin{array}{c}\text { RP24- } \\
\text { (4) }\end{array}$ & TCF15 & S100A8 \\
\hline 4 & OSR2 & GPIHBP1 & BCL2A1B & COMP & ELAVL4 & ABCC9 & CLDN19 & MMD2 & ACTA2 & S100A9 \\
\hline 5 & LUM & SLCO1A4 & C1QC & SLC4A10 & SCG2 & COLEC11 & MLIP & ACSBG1 & MYH11 & LTF \\
\hline 6 & A2M & GRRP1 & CCL4 & H19 & STMN2 & TRPC6 & PRX & LRRTM1 & KCNA5 & 1100001G20RIK \\
\hline 7 & CCL11 & PLVAP & CD74 & IGF2 & RPRM & KCNE4 & PMP2 & DHRS2 & TAGLN & RETNLG \\
\hline 8 & APOD & FLT1 & C1QA & PROK2 & TRPV1 & RGS5 & KCNK1 & TEX40 & MAP3K7CL & LCN2 \\
\hline 10 & CO30408B16RIK & RBP7 & MS4A6C & DIO2 & EEF1A2 & AGTR1A & IL17B & GM2115 & TESC & LY6G \\
\hline
\end{tabular}

Rat

\begin{tabular}{|c|c|c|c|c|c|c|c|c|}
\hline $\begin{array}{c}\text { Top } \\
\text { genes }\end{array}$ & $\begin{array}{c}\text { Connective } \\
\text { Tissue }\end{array}$ & Endothelial & Macrophage & Mesenchymal & Neuron & Pericytes & $\begin{array}{c}\text { Schwann } \\
\text { cell }\end{array}$ & sGC \\
\hline $\mathbf{1}$ & SCARA5 & CLDN5 & C1QA & CLDN11 & ADCYAP1 & KCNJ8 & MAG & TYRP1 \\
\hline $\mathbf{2}$ & POSTN & FLT1 & LYZ2 & KCNJ13 & SCG2 & RGS5 & SLC36A2 & IGFBP2 \\
\hline $\mathbf{3}$ & CRISPLD2 & CYYR1 & C1QC & GZMM & SNHG11 & ACTA2 & CLDN19 & CSN1S1 \\
\hline $\mathbf{4}$ & LOC100911545 & SLCO14A & C1QB & SLC16A11 & CALCB & NDUFA4L2 & NCMAP & SCRG1 \\
\hline
\end{tabular}


bioRxiv preprint doi: https://doi.org/10.1101/2021.04.17.440274; this version posted April 18, 2021. The copyright holder for this preprint (which was not certified by peer review) is the author/funder. All rights reserved. No reuse allowed without permission.

\begin{tabular}{|c|c|c|c|c|c|c|c|c|c|c|}
\hline $\mathbf{5}$ & DNAH11 & FAM110D & TYROBP & ALDH1A3 & NTRK1 & CCL19 \\
\hline $\mathbf{6}$ & RBP4 & ABCG2 & AIF1 & IGFBP6 & RIT2 & HIGD1B & KCNK1 \\
\hline $\mathbf{7}$ & GAD1 & SOX17 & FCER1G & CPXM2 & PCBD1 & NPY1R & BCAS1 \\
\hline $\mathbf{8}$ & MYOC & PROM1 & CCL4 & KLF5 & SYT1 & RASL11A & PRX \\
\hline $\mathbf{9}$ & SRPX & ADGRL4 & CXCL2 & GJB2 & LAMP5 & INPP4B & KCNA1 \\
\hline $\mathbf{1 0}$ & MEOX1 & PLVAP & CCL6 & TBATA & NSG2 & ADRA2A \\
\hline
\end{tabular}


Table 2 Top expressed ion channels and receptors in human SGC

\begin{tabular}{|c|c|c|c|}
\hline Gene symbol & Channel type & Gene symbol & Receptor type \\
\hline KCNE4 & Potassium channels & GRIK2 & Glutamate receptors \\
\hline KCNH8 & Potassium channels & GRIK3 & Glutamate receptors \\
\hline KCNJ3 & Potassium channels & GRIN2B & Glutamate receptors \\
\hline KCNK1 & Potassium channels & CHRM3 & Cholinergic Receptors \\
\hline KCNMA1 & Potassium channels & P2RY14 & Purinergic receptors \\
\hline KCNMB4 & Potassium channels & GABRB3 & GABA receptors \\
\hline SCN7A & Sodium channels & HCN1 & 5-HT receptors \\
\hline SCN9A & Sodium channels & & \\
\hline NALCN & Sodium channels & & \\
\hline CACNA1D & Calcium channels & & \\
\hline CACNA2D1 & Calcium channels & & \\
\hline CACNB4 & Calcium channels & & \\
\hline TRPC1 & TRP channels & & \\
\hline TRPM3 & TRP channels & & \\
\hline TRPM7 & TRP channels & & \\
\hline PKD2 & TRP channels & & \\
\hline ANO1 & Chloride channels & & \\
\hline ANO10 & Chloride channels & & \\
\hline ANO6 & Chloride channels & & \\
\hline CLIC4 & Chloride channels & & \\
\hline CLCN3 & Chloride channels & & \\
\hline ITPR1 & other channels & & \\
\hline ITPR2 & other channels & & \\
\hline ITPR3 & other channels & & \\
\hline TPCN1 & other channels & & \\
\hline
\end{tabular}


Figuregeneff preprint doi: https://doi.org/10.1101/2021.04.17.440274; this version posted April 18, 2021. The copyright holder for this preprint (which
was not certified by peer review) is the author/funder. All rights reserved. No reuse allowed without permission.

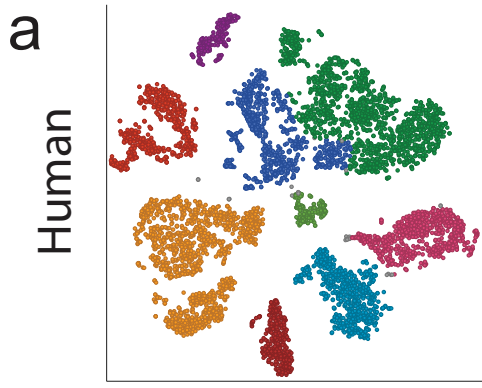

- Connective Tissue

- Endothelial

Mesenchyma

mysc

$n m S C$

SGC

Smooth Muscle

T-cells

6443 points

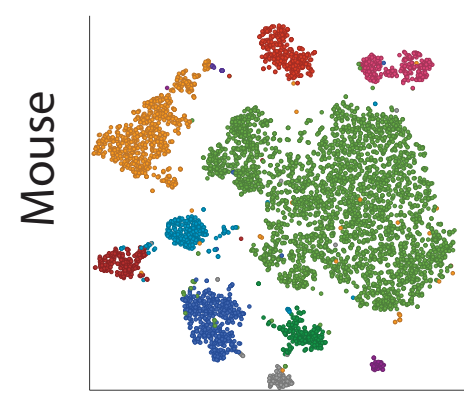

Connective Tissue

Endothelial
Macrophages

Mesenchyma

Neurons

Pericytes

Schwann cells

SGC

Smooth Muscle Cells

T-cells

6251 points

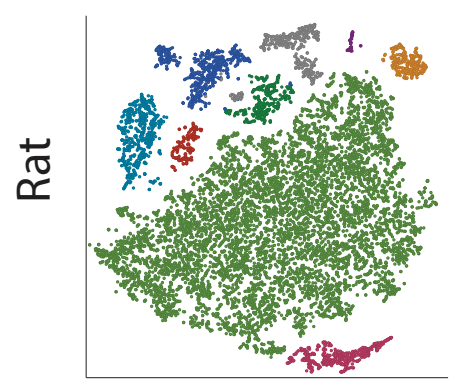

- Connective tissue

Endothelial

Macrophages

Mesencymal

Neurons

- Pericytes

Schwann cells

SGC

N/A

11432 points

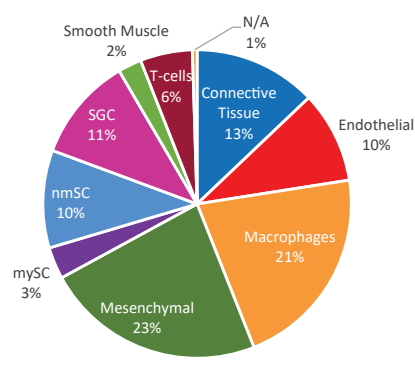

b
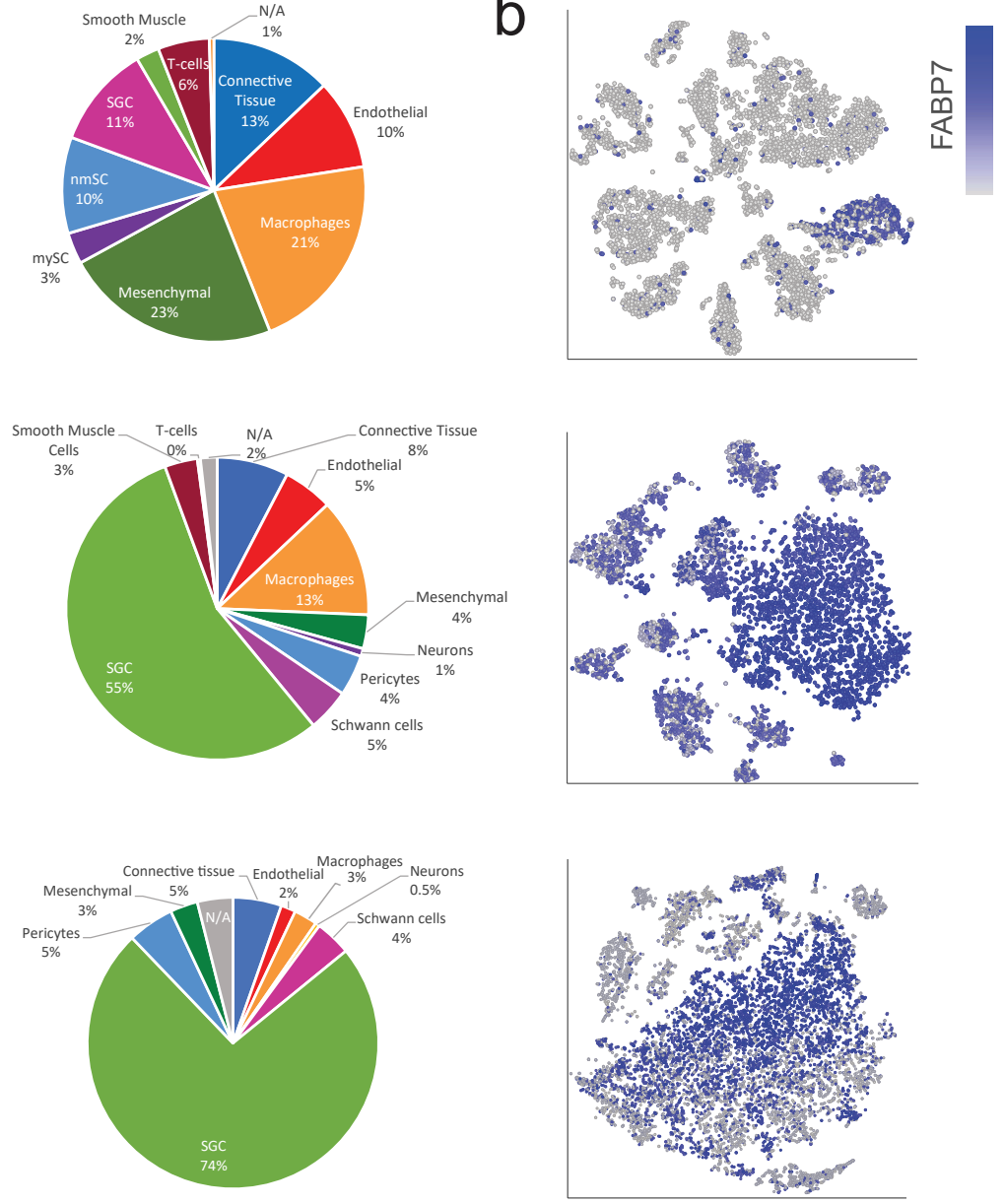
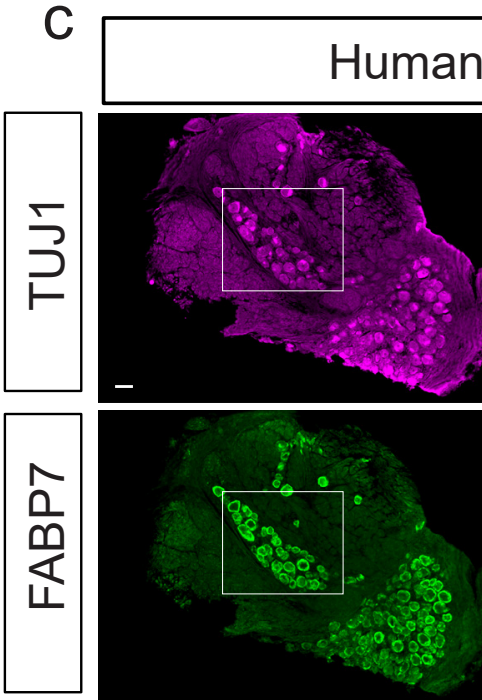

\begin{tabular}{|l|}
\hline (1) \\
Ð \\
$\sum$
\end{tabular}

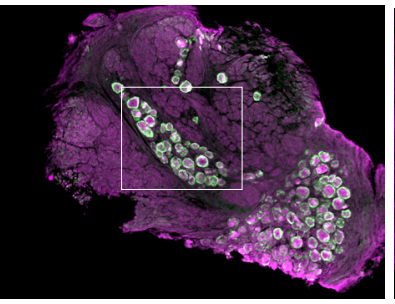

\section{DRG}
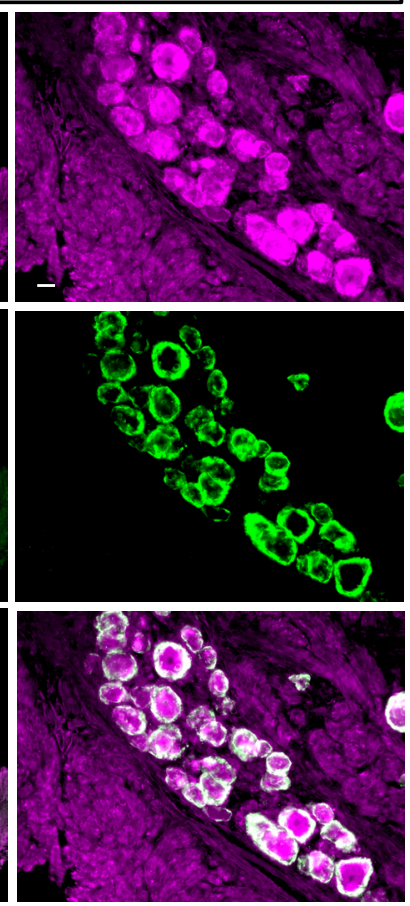

d
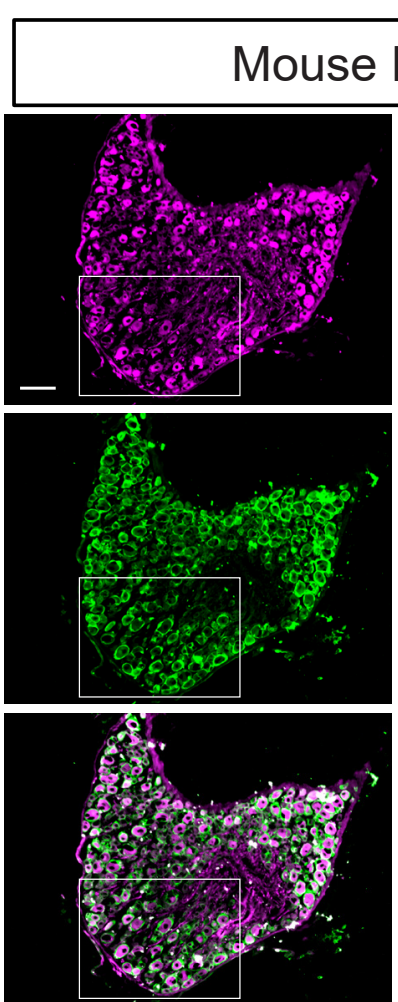

DRG
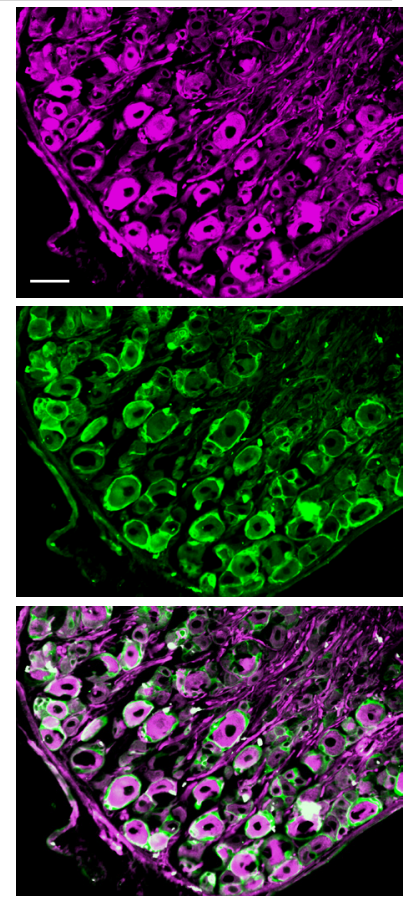


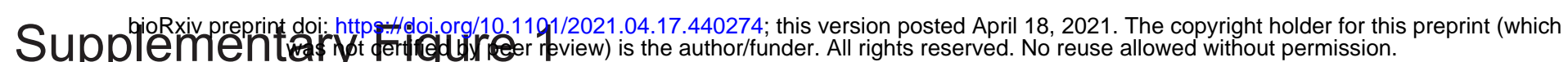

a

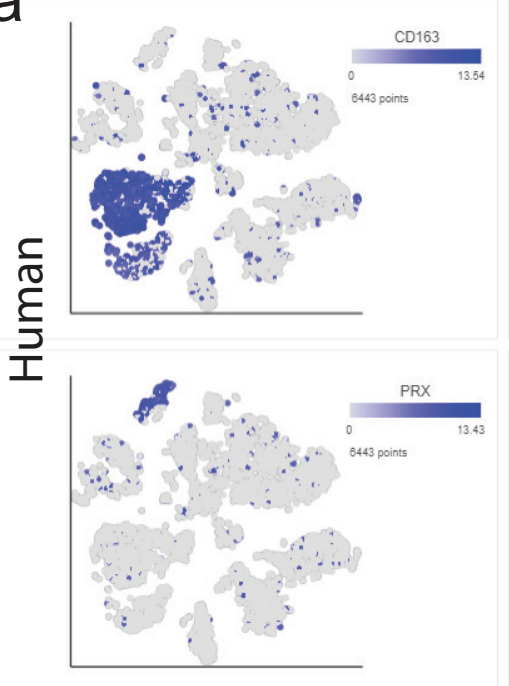

b

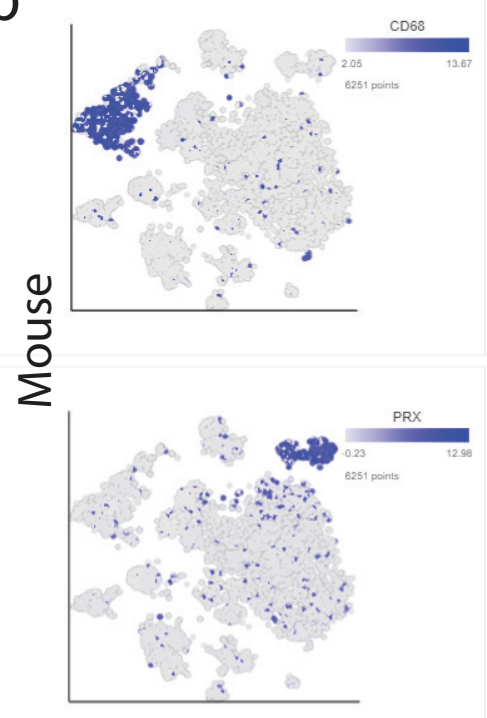

C

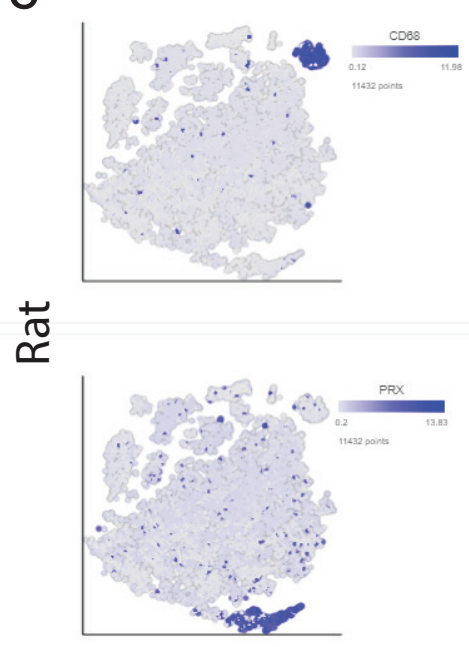

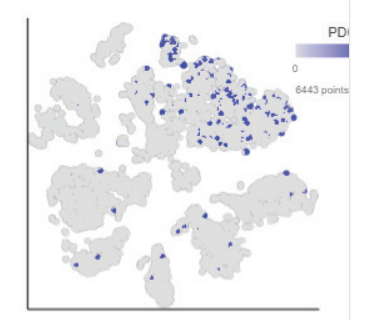
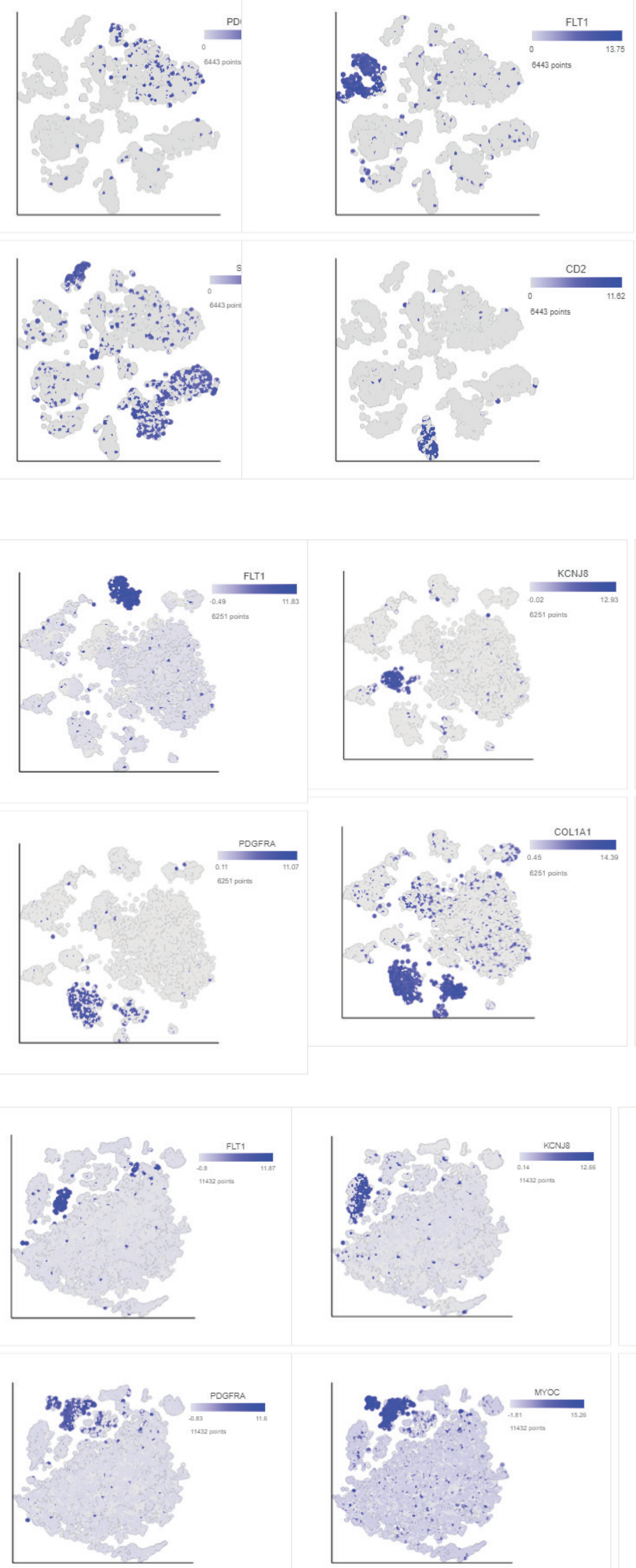
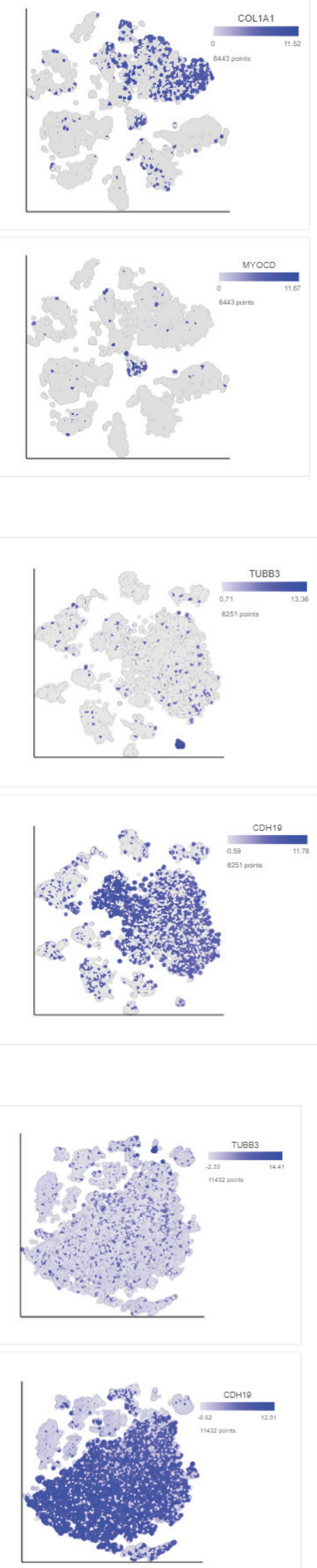
bioRxiypreprint doi: https://doi.org/10.1101/2021.04.17.440274; this version posted April 18, 2021. The copyright holder for this preprint (which
was not certified by peer review) is the author/funder. All rights reserved. No reuse allowed without permission. FIgure 2 was not certified by peer review) is the author/funder. All rights reserved. No reuse allowed without permission.

a Human

t-SNE

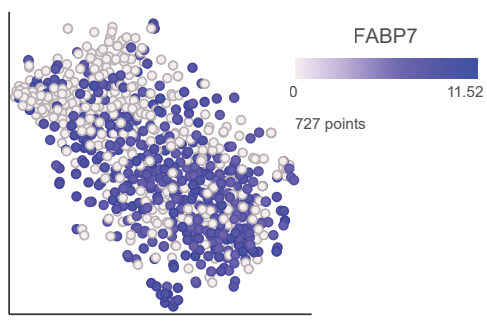

$\mathrm{t}-\mathrm{SNE}$

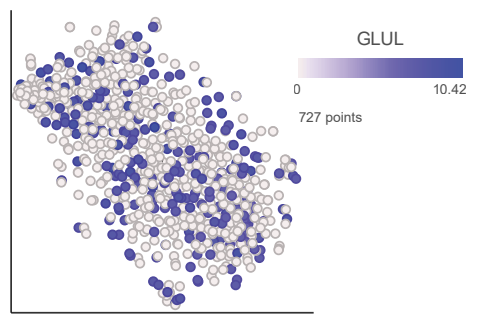

C

Rat

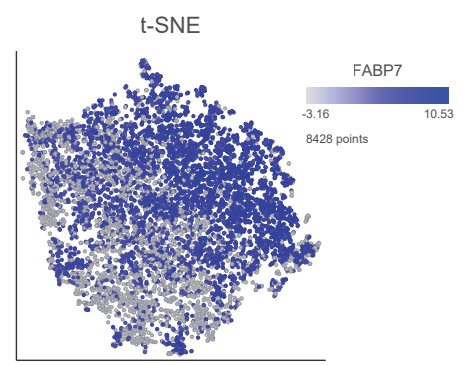

t-SNE

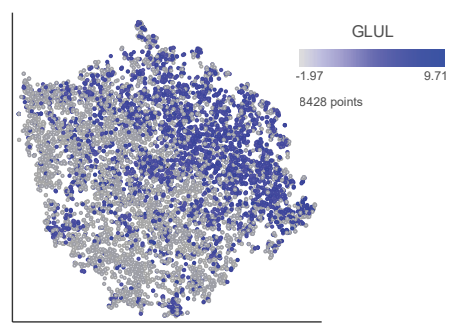

e

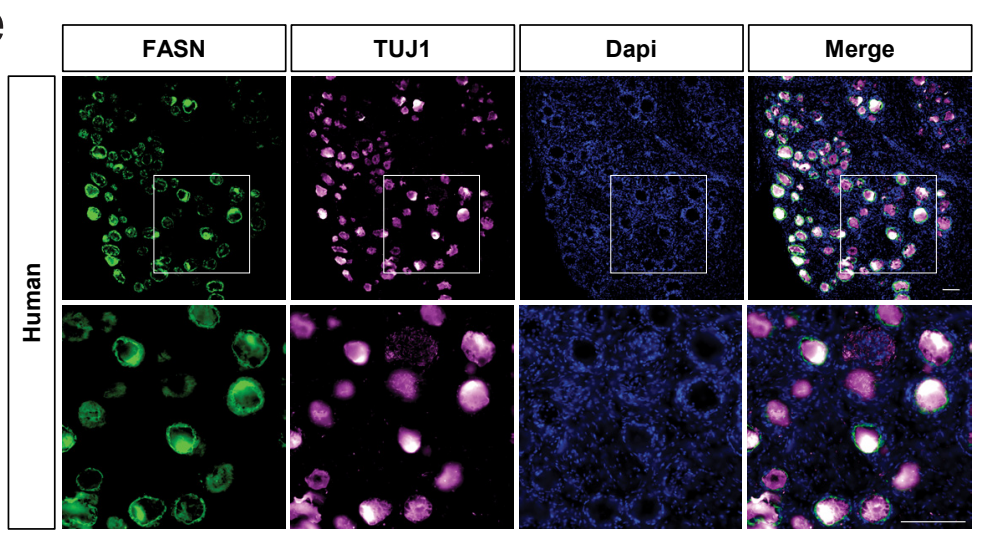

b

t-SNE

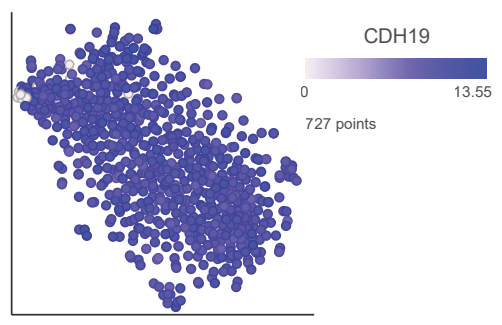

t-SNE

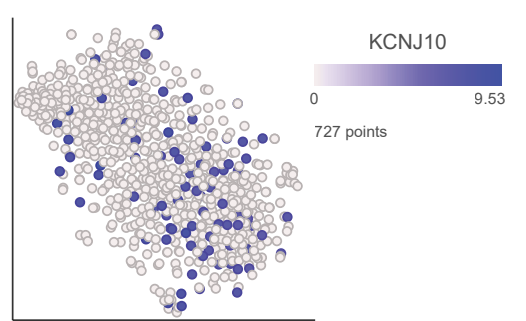

d
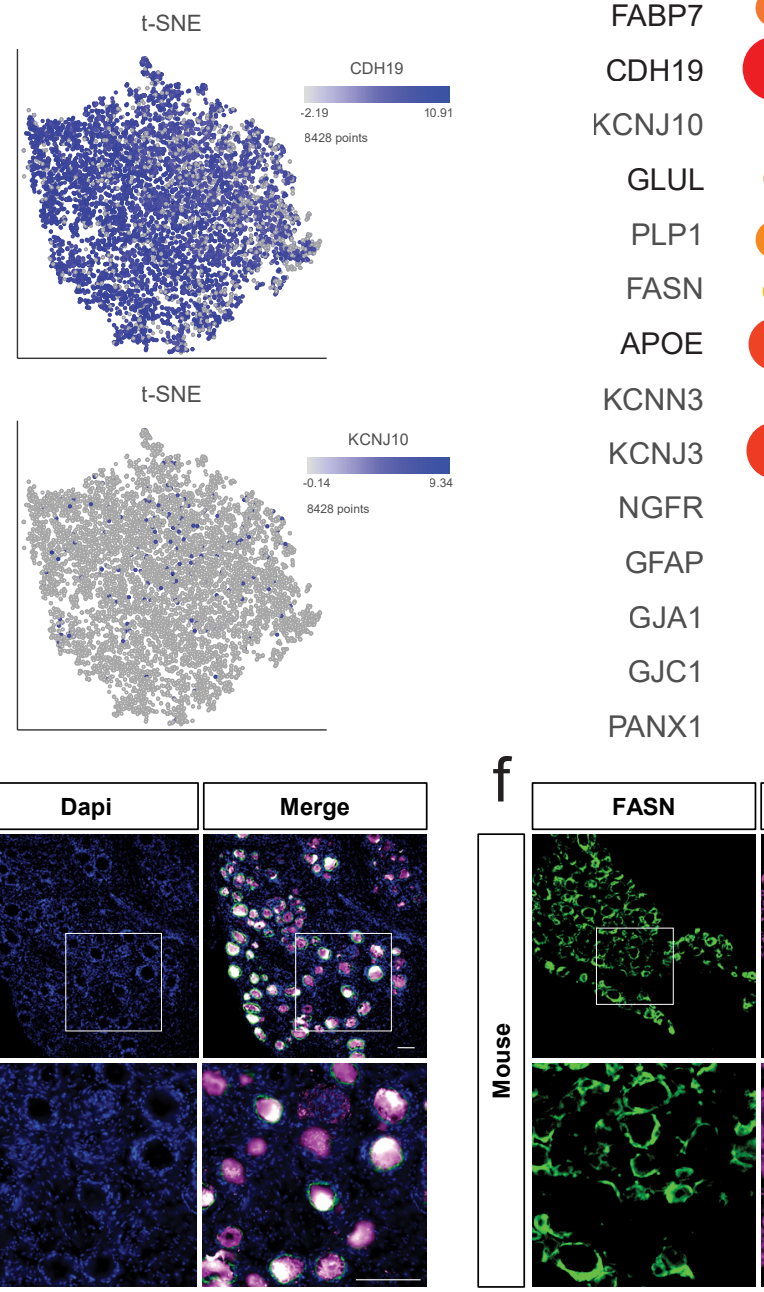

KCNN3

KCNJ3

NGFR

GFAP

GJA1

GJC1

PANX1
Mouse
t-SNE

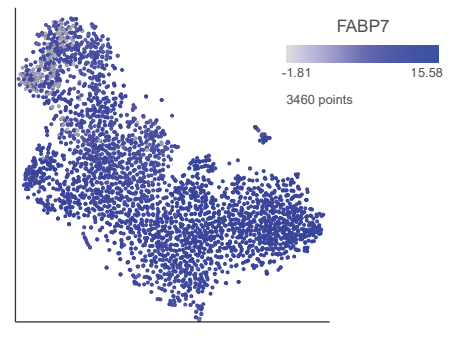

t-SNE

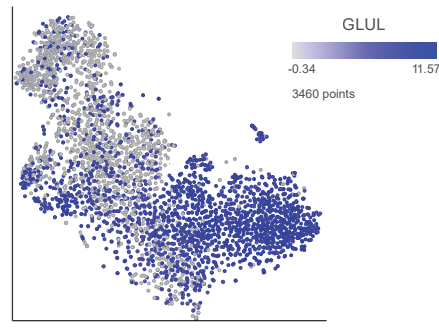

t-SNE

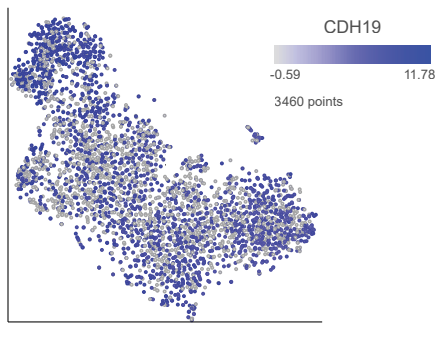

t-SNE

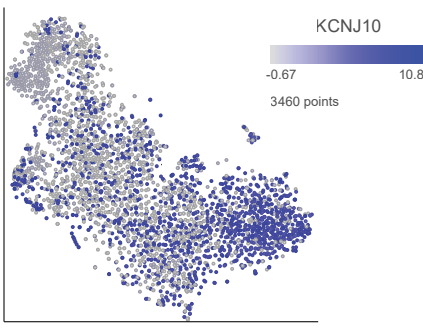

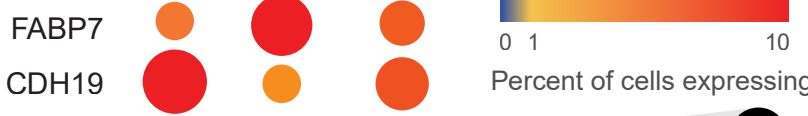

KCNJ10 • .
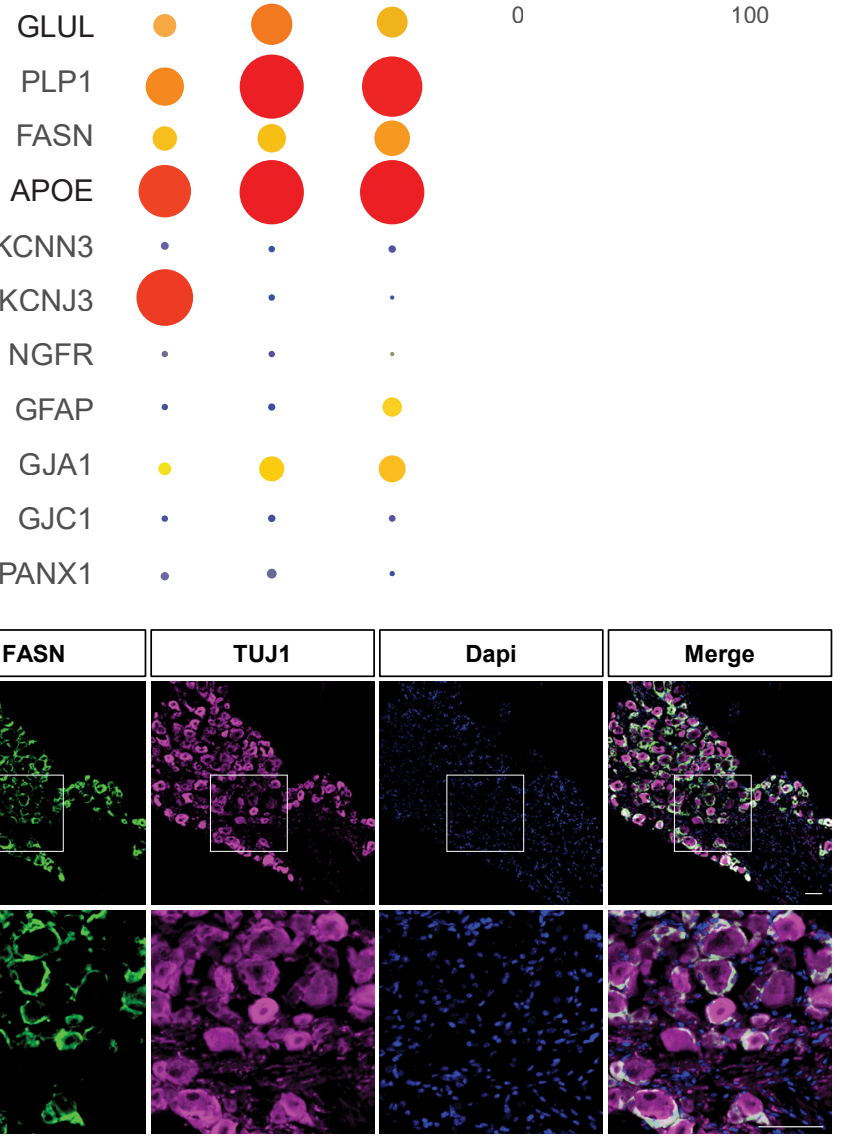
Eidurbioniz preprint doi: https://doi.org/10.1101/2021.04.17.440274; this version posted April 18, 2021. The copyright holder for this preprint (which was not certified by peer review) is the author/funder. All rights reserved. No reuse allowed without permission.

a

\section{Human SGC}

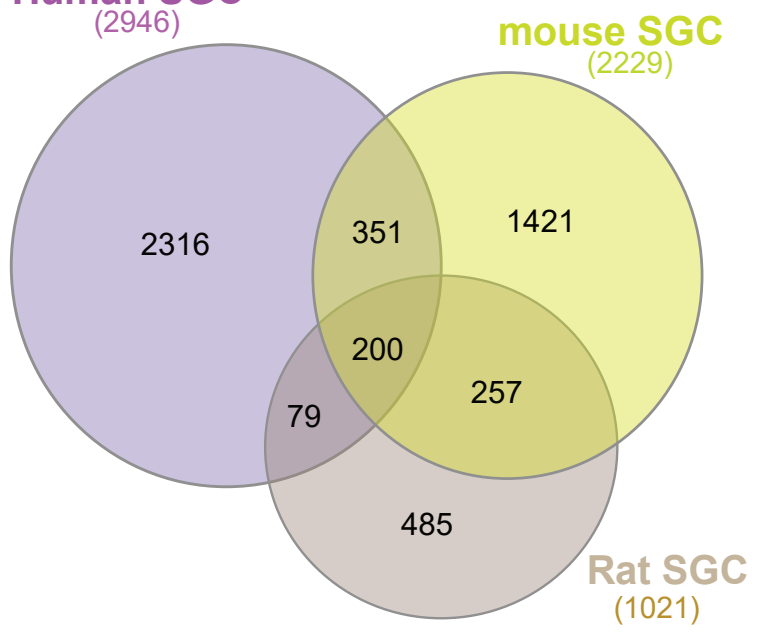

C

\section{Mouse}

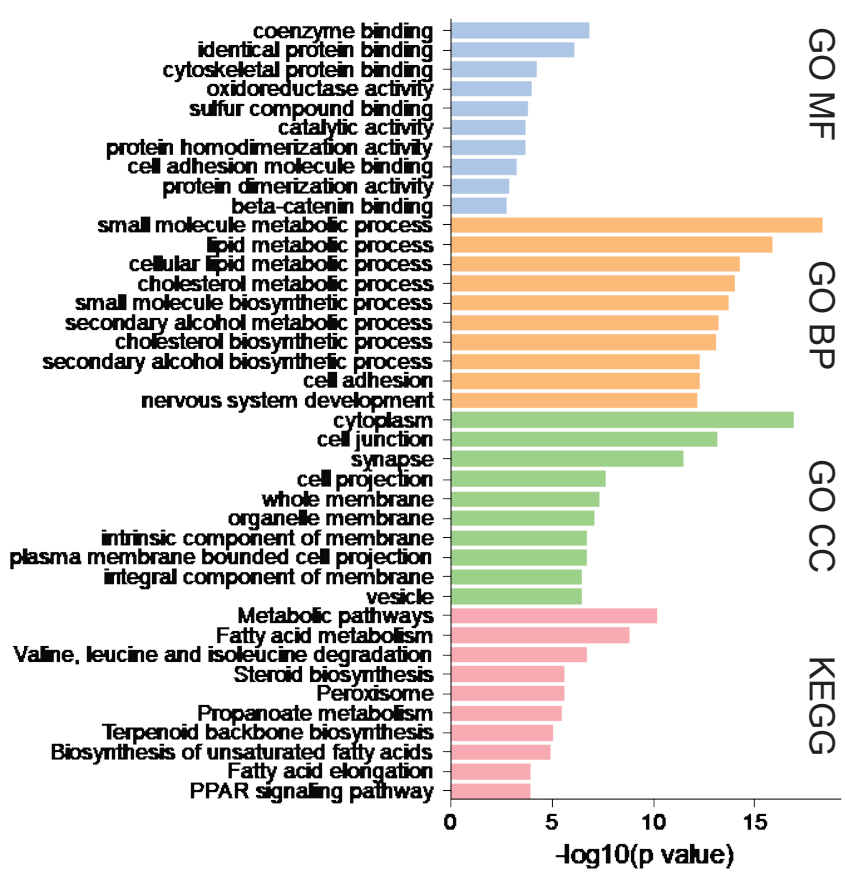

b

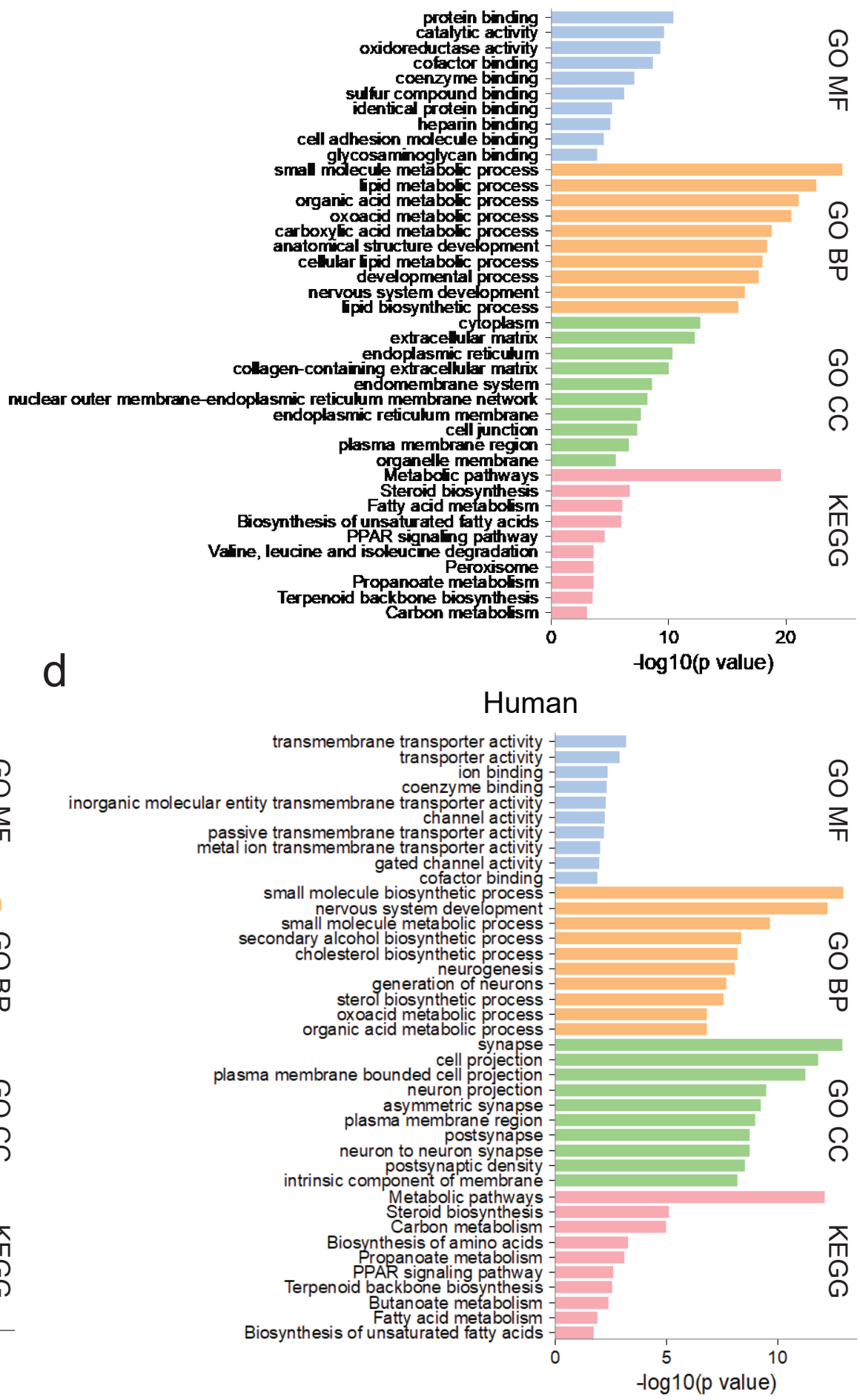

\section{Rat}


Fidupioxiypreprint doi: https://doi.org/10.1101/2021.04.17.440274; this version posted April 18, 2021. The copyright holder for this preprint (which was not certified by peer review) is the author/funder. All rights reserved. No reuse allowed without permission.

a

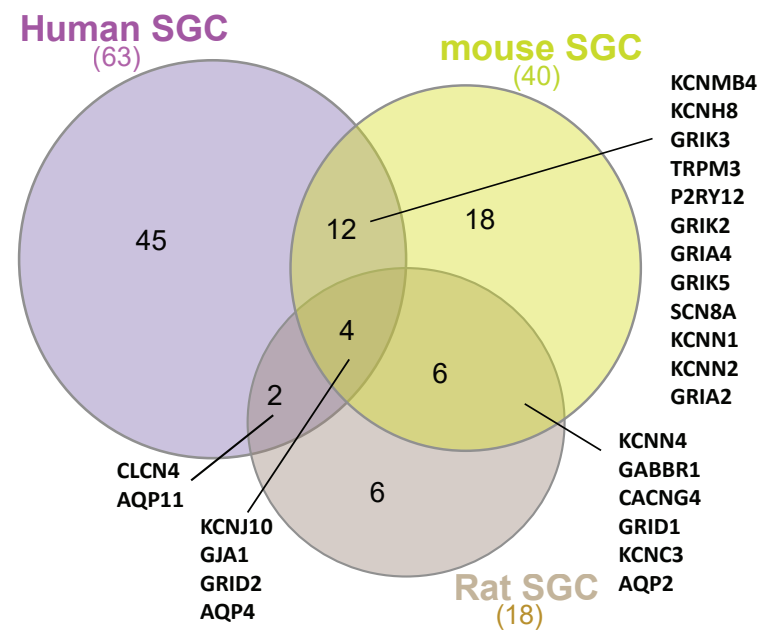

b

\begin{tabular}{|c|c|c|c|}
\hline Channel/receptor type & Human & Mouse & Rat \\
\hline Potassium channels & $\begin{array}{l}\text { KCNJ3, KCNE4, KCNJ10, KCNK1, } \\
\text { KCNS3, KCNA2, KCNV2, KCND2, } \\
\text { KCNH7, KCNJ13, KCNH5, KCNH6, } \\
\text { KCNMB4, KCNH8,, KCNN1, KCNN2 }\end{array}$ & $\begin{array}{l}\text { KCNA1, KCNA6, } \\
\text { KCNJ16, KCNH2, } \\
\text { KCNK13, KCNJ10, } \\
\text { KCNMB4, KCNH8, } \\
\text { KNN1, KCNN2, KCNN4, } \\
\text { KCNC3 }\end{array}$ & $\begin{array}{l}\text { KCNJ10, KCNN4, } \\
\text { KCNC3, KCNN3 } \\
\text { SCNN1G, KCNK3 }\end{array}$ \\
\hline Sodium channels & $\begin{array}{c}\text { SCN9A, SCN2A, SCN1A, SCN2B, } \\
\text { SCN8A, SCN4B }\end{array}$ & SCN3B, SCN7A, SCN8A & \\
\hline Water channels & AQP4, AQP11 & $\begin{array}{c}\text { AQP3, AQP9, AQP4, } \\
\text { AQP2 }\end{array}$ & AQP4, AQP11, AQP2 \\
\hline Calcium channels & CACNA2D1, CACNA1D & CACNG4 & CACNG4 \\
\hline TRP channels & $\begin{array}{l}\text { TRPV3, TRPV5, MCOLN3, MCOLN2, } \\
\text { PKD2L2, TRPM3 }\end{array}$ & TRPM3 & \\
\hline Chloride channels & $\begin{array}{c}\text { ANO1, ANO5, ANO8, ANO3, CLIC4, } \\
\text { BEST1, CLCN4 }\end{array}$ & CLCN3 & CLCN4, CLIC6 \\
\hline Glutamate receptors & $\begin{array}{l}\text { GRIN2B, GRID2, GRIK3, GRIK2, } \\
\text { GRIA4, GRIK5, GRIA2, GRM5, GRM7 }\end{array}$ & $\begin{array}{l}\text { GRIA3, GRID2, GRIK3, } \\
\text { GRIK2, GRIA4, GRIK5, } \\
\text { GRIA2, GRID1 }\end{array}$ & GRID2, GRID1 \\
\hline Cholinergic receptors & CHRM3, CHRM5 & & \\
\hline Purinergic receptors & P2RY14, P2RX6, P2RY12 & P2RX7, P2RX5, P2RY12 & \\
\hline GABA receptors & GABRB3, GABRB1 & GABRE, GABBR1 & $\begin{array}{l}\text { GABBR1, GABRG1, } \\
\text { GABRA3 }\end{array}$ \\
\hline 5-HT receptors & HTR2A, HTR2C & & \\
\hline $\begin{array}{l}\text { Cyclic nucleotide- } \\
\text { regulated }\end{array}$ & CNGA1, CNGB3 & & \\
\hline Gap-junction & PANX2, GJA1 & GJC3, PANX1, GJA1 & GJA1 \\
\hline Other & TPCN1, ITPR2 & ITPR3, CATSPER3 & \\
\hline
\end{tabular}

C

\section{Human}

Neuroactive ligand-receptor interactionCalcium signaling pathway

Serotonergic synapse

Glutamatergic synapse

Retrograde endocannabinoid signaling Cholinergic synapse

Dopaminergic synapse Gap junction Nicotine addiction Inflammatory mediator regulation of TRP channels Oxytocin signaling pathway Long-term potentiation

\section{Mouse}

Neuroactive ligand-receptor interactionRetrograde endocannabinoid signalingNicotine addictionCalcium signaling pathwayNOD-like receptor signaling pathwayLong-term depressionGastric acid secretionCircadian entrainmentGlutamatergic synapseDopaminergic synapse-

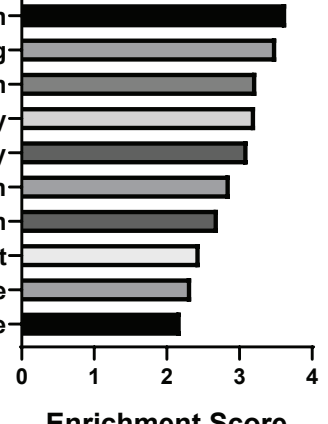

Enrichment Score

Rat

Neuroactive ligand-receptor interactionTaste transductionGABAergic synapseMorphine addiction Nicotine addiction-

Vasopressin-regulated water reabsorptionInsulin secretion

Retrograde endocannabinoid signaling Aldosterone-regulated sodium reabsorption-

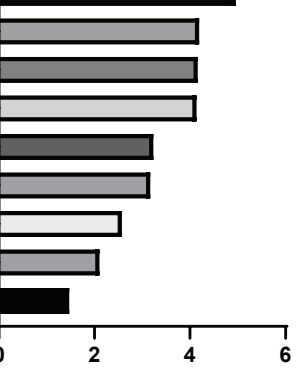

Enrichment Score 
bioRxiv preprint doi: https://doi.org/10.1101/2021.04.17.440274; this version posted April 18, 2021. The copyright holder for this preprint (which

Figure 5 was not certified by peer review) is the author/funder. All rights reserved. No reuse allowed without permission.

a

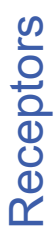

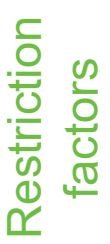

$\infty$
0
क
$\mathbb{0}$
$\frac{0}{0}$
$\frac{0}{\square}$

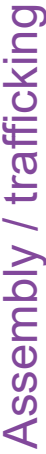

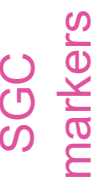

0
0
0
0
0

0

TMPRSS2 •

TMPRSS11A

TMPRSS4

ITM3

IFITM2

LY6E

CTSB

CTSL

RHOA

RAB1A

RAB10

RAB14

CAV1

AP2A2

TAPT1

CHMP2A

TOP3B

FABP7

$\mathrm{CDH} 19$

GLUL

APOE
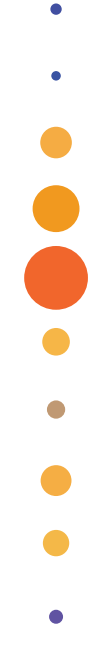

\section{Human Mouse Rat}
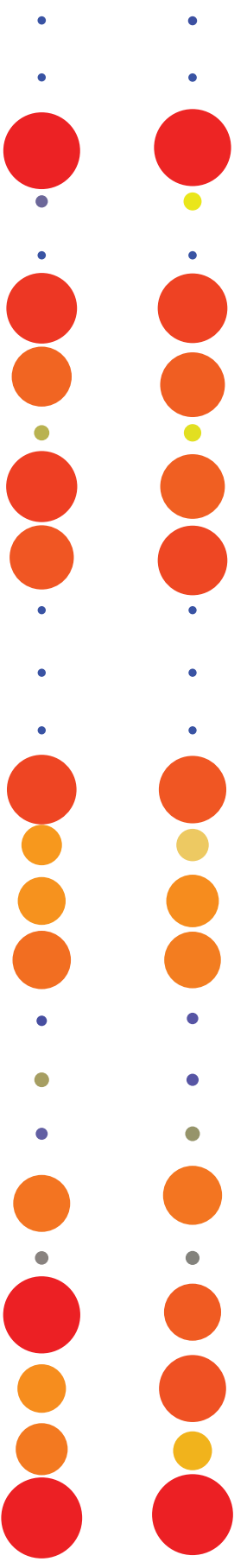

01

10

Percent of cells expressing

100

b
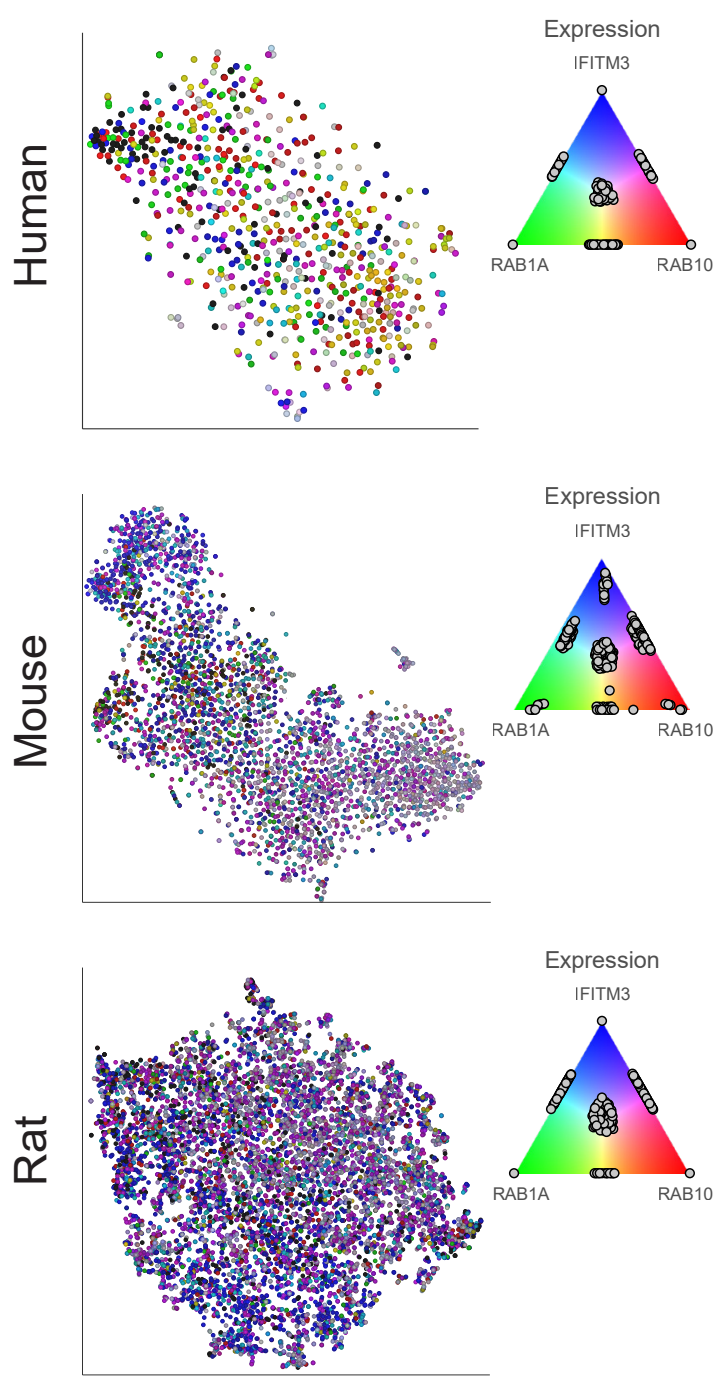